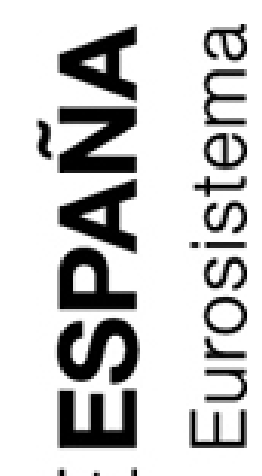

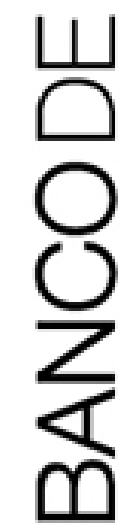

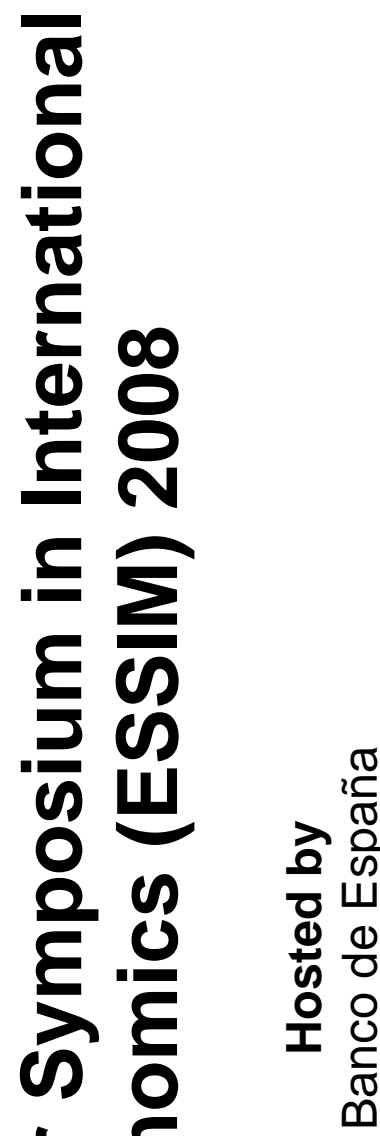

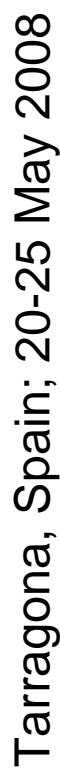
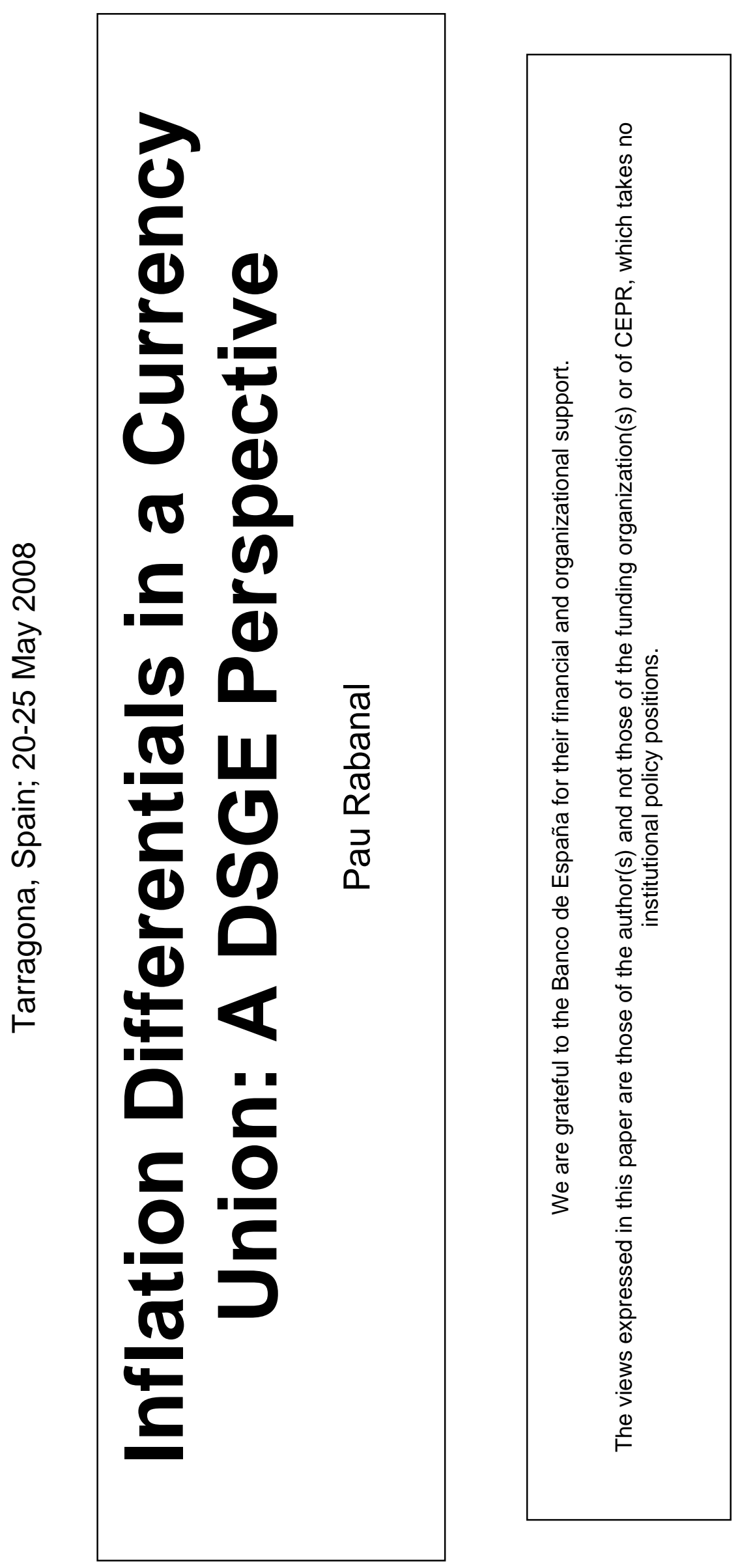

(1)

E 0

E

(1)

E

(4)

后

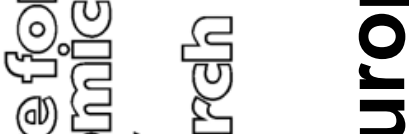

농 (2)

जिए (0)

(ब) (0) (0)

UiI.

(1) 


\title{
Inflation Differentials in a Currency Union: A DSGE Perspective
}

\author{
Pau Rabanal* \\ Caixa d'Estalvis i Pensions de Barcelona
}

May 15, 2008

\begin{abstract}
Cross country studies of inflation differentials, and in particular in the EMU, have focused on three main explanations: (i) the role of tradable and nontradable sector productivity growth differentials and the BalassaSamuelson effect, (ii) the role of the demand-side effects, and (iii) heterogeneity of inflationary processes inside the EMU. To understand the role played by each feature in shaping inflation differentials, this paper estimates a two country, two sector Dynamic Stochastic General Equilibrium (DSGE) model with nominal rigidities in a currency union using data for Spain and the euro area. The paper finds that productivity shocks in both sectors are the most important source of inflation differentials, explaining about 75 percent of its variability. Demand shocks explain a large fraction of output growth variability, but not variability in inflation differentials. In addition, the estimated model finds evidence that inflation dynamics are different in Spain and in the rest of the euro area. Finally, the Balassa-Samuelson effect does not appear to be important during the EMU period.
\end{abstract}

JEL Classification: F41, F42, C51.

Keywords: Balassa-Samuelson effect, Bayesian Estimation, European Monetary Union.

*Research Department (9012), Caixa d'Estalvis i Pensions de Barcelona, Torre 1, Planta 6, Avinguda Diagonal 621-629, 08028 Barcelona. Email: prabanal@lacaixa.es. I am thankful to Jordi Galí, Juan Rubio-Ramírez, and Christopher Sims for very helpful comments and suggestions. The views expressed in this paper are those of the author only and should not be attributed to Caixa d'Estalvis i Pensions de Barcelona ("la Caixa"). 


\section{Introduction}

Since the launch of the common european currency, the euro, in January 1999, a topic that has received a lot of attention is the study of inflation differentials in the Economic Monetary Union (EMU). ${ }^{1}$ At the time the euro and the common monetary policy were introduced, the Harmonised Index of Consumer Prices (HICP) was increasing at a 12-month rate of 0.9 percent for the EMU, with a weighted standard deviation of 1.1 percent across countries. Eight years later, in December 2006, the EMU inflation rate was at 1.9 percent, while the weighted standard deviation was 1.9 percent. This increase both in inflation and inflation dispersion can be striking given that in January 1999, EMU countries seemed to have achieved nominal convergence. Figure 1 plots the weighted standard deviation of the 12-month inflation rate, and its components (goods and services). Clearly, after an all-time low in 1999, inflation dispersion has increased significantly since, albeit with some fluctuations. While most of the time there has been higher dispersion in services inflation, in two episodes (between early 2000 to mid-2001, and between late-2005 and late-2006) the opposite has happened, and the goods category has in fact displayed more dispersion across EMU countries.

Another interesting feature of the recent period is the persistence of inflation differentials. Even when long periods of time are considered, some member countries have persistently experienced higher inflation rates than the EMU as a whole. Table 1 shows the average 12-month HIPC inflation rates for the January 1999 - December 2006 period for the 12 countries of the EMU. While EMU has been on average right above the ECB's target of 2 percent inflation, there are some important crosscountry differences. Some countries have been, on average, close or below the ECB target (Austria, France, Belgium, Finland and Germany); while, on the other hand, some countries have been significantly above the target: well known examples in this last group are Spain, with a seven-year average 12-month inflation rate of 3.2 percent, and Ireland, with 3.5 percent. Table 1 also shows that inflation in the services component of the HICP has been higher than in the goods component, and that the national pattern that we observe for the headline HICP also holds for its goods, services, and core (excluding food and energy) components.

\footnotetext{
${ }^{1}$ See for instance ECB (2003), Angeloni and Erhmann (2007), López-Salido et al. (2005), Andrés et al. (2003).
} 


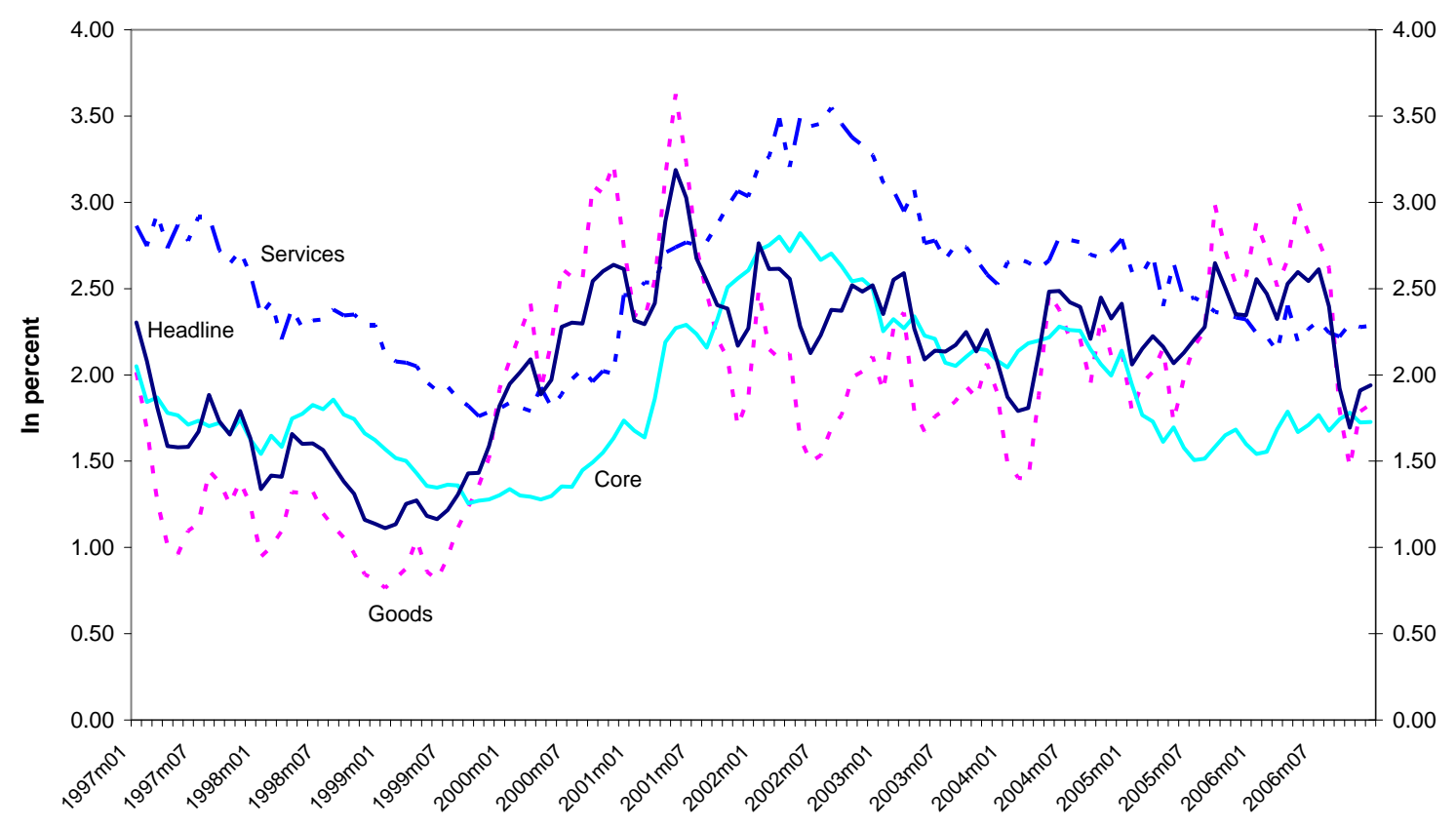

Figure 1: Weighted standard deviation of the 12-month inflation rate in the EMU. Source: Eurostat and author's calculations.

Table 1. Average 12-month HICP inflation rates.

Euro area, 1999-2006

\begin{tabular}{lcccc}
\hline & HICP & Goods & Services & Core \\
\hline & & & & \\
EMU & 2.06 & 1.92 & 2.26 & 1.67 \\
Belgium (BE) & 2.01 & 1.93 & 2.11 & 1.50 \\
Germany (DE) & 1.48 & 1.59 & 1.34 & 1.01 \\
Greece (GR) & 3.24 & 3.00 & 3.68 & 3.61 \\
Spain (ES) & 3.15 & 2.82 & 3.78 & 2.70 \\
France (FR) & 1.80 & 1.61 & 2.09 & 1.42 \\
Ireland (IE) & 3.45 & 2.29 & 4.98 & 2.98 \\
Italy (IT) & 2.33 & 2.13 & 2.72 & 2.19 \\
Luxemburg (LU) & 2.75 & 2.73 & 2.60 & 2.11 \\
Netherlands (NL) & 2.52 & 2.18 & 2.85 & 1.94 \\
Austria (AT) & 1.69 & 1.28 & 2.19 & 1.37 \\
Portugal (PT) & 3.00 & 2.40 & 3.94 & 2.62 \\
Finland (FI) & 1.55 & 1.01 & 2.41 & 1.32 \\
\hline
\end{tabular}

Source: Eurostat and author's calculations 
Cross country studies of inflation dynamics, and in particular in the EMU, have focused on three main explanations. The first one brings back the well-known Balassa-Samuelson effect (Altissimo et al., 2005). The second one studies the role of the demand-side effects (López-Salido et al., 2005). The third one studies heterogeneity of inflationary processes inside the EMU (Angeloni and Ehrmann, 2007), which could make inflation differentials highly persistent, even when all countries are hit by the same symmetric shocks (for instance, oil prices, or fluctuations of the euro).

The Balassa-Samuelson effect is typically used to explain inflation differentials for those countries experiencing a catching-up process. As the relatively poorer countries adopt new technologies and get closer to the most advanced countries, they will necessarily experience higher real GDP growth, increased wages, and higher inflation. The Balassa-Samuelson effect can be stated as follows: suppose that the sectors of an economy that are open to international trade (the "tradable" sectors) experience high productivity growth relative to those sectors not open to international trade (the "nontradable" sectors). This can happen, as in the case of the EMU, when a group of countries increase economic integration, barriers to trade fall, and hence it is easier to import more productive technologies from the more advanced countries. Higher productivity in the tradable sector increases the marginal product of labor in that sector, and therefore labor demand. This puts upward pressure on wages, which increase for the whole economy. Since prices are set as a markup over production costs, inflation increases in the nontradable sector, that do not benefit from productivity improvements but face higher wages. The effect of productivity improvements on tradable inflation in the short term is less clear, but typically the real wage increases by less than the level of productivity, and tradable sector inflation declines. Therefore, the Balassa-Samuelson hypothesis could be a candidate to explain the higher inflation rate in the service sector (that does not benefit from productivity improvements) than in the goods sector, and hence leading to higher headline HICP inflation. ${ }^{2}$

At first sight, this story seems to fit the EMU experience: Spain and Ireland, for instance, have experienced above-average real GDP growth and above-average in-

\footnotetext{
${ }^{2}$ Regarding inflation differentials in the tradable sector, as trade barriers fall and countries adopt a common currency (hence, price comparisons are easier), then price level convergence implies that some countries will experience higher inflation rates than others in the transition. However, Rogers (2006) finds that price level convergence in the EMU seemed to happen already during the 1990s, and that current levels of price dispersion across european cities are similar to those in the USA.
} 


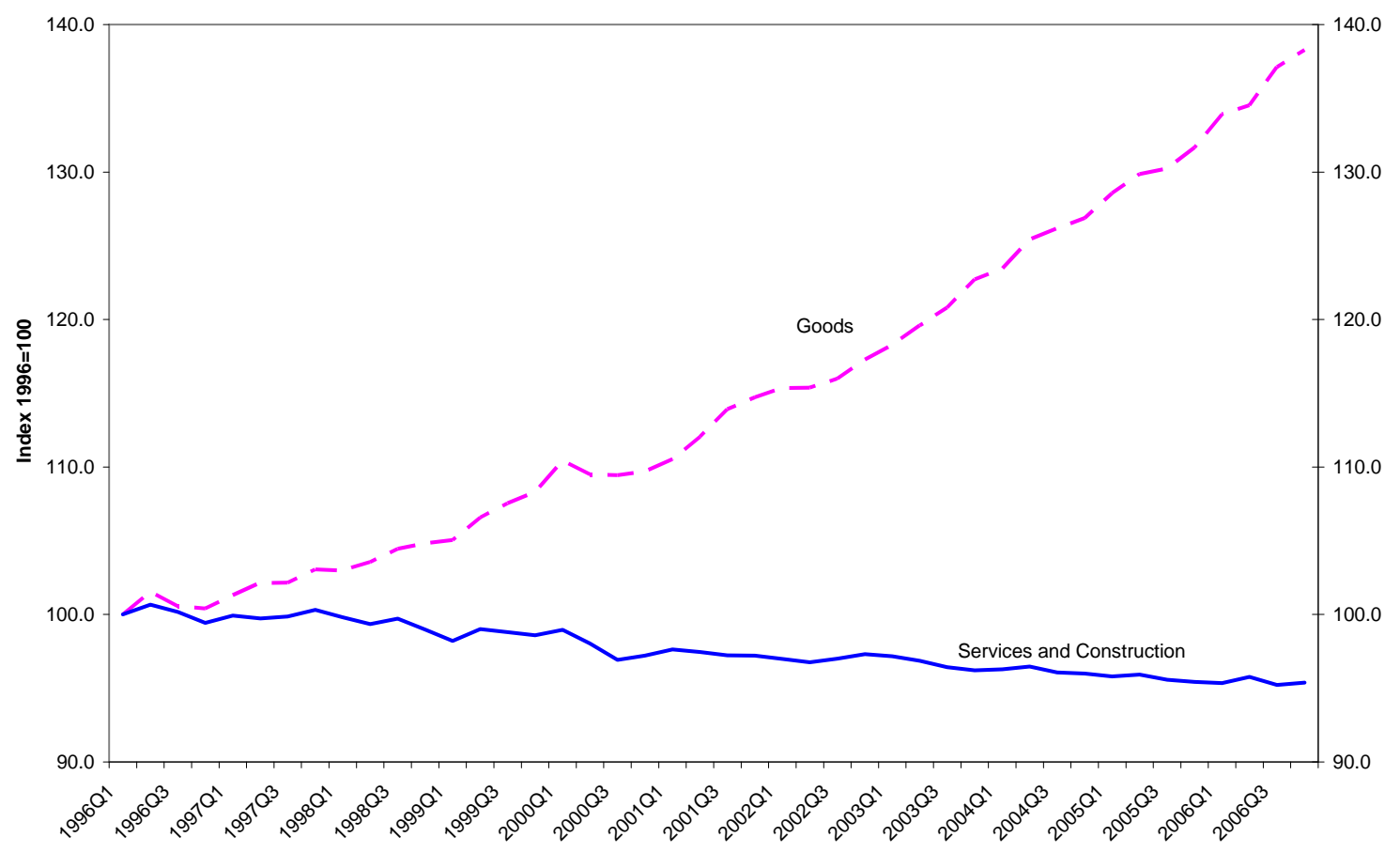

Figure 2: Spain. Labor productivity in the tradable (goods) and nontradable (services and construction) sectors. Source: INE.

flation. In Spain, labor productivity growth has been much higher in the tradable (goods) sector than in the nontradable (services and construction) sector. Figure 2 plots labor productivity in the two sectors (defined as output per employee): in fact, productivity in the nontradable sector has been experiencing negative growth rates in recent years. Hence, as López-Salido et al. (2005) point out, it is difficult to square the evidence on productivity and inflation with the recent growth figures in Spain. Spain has been experiencing solid growth in the recent years: during the period 1999-2006, real annual GDP growth in Spain has averaged 3.2 percent, while it has averaged 2 percent in the EMU. In addition, the nontradable sector (services and construction) has grown at an average rate of 3.5 percent, compared to a real growth rate in the tradable sector of 2.5 percent. Therefore, supply (productivity) factors cannot be the only explanation for the evolution of the inflation differential between Spain and the EMU, because declining productivity in the nontradable sector would imply higher inflation but lower output in this sector, but output has increased due to higher employment. Therefore, to observe both an increase of output and prices in the nontradable sector, demand factors must have played an important role.

Finally, Angeloni and Ehrmann (2007), and Andrés et al. (2003) suggest that, due 
to different product and labor market structures, there is heterogeneity of inflation dynamics processes in each country of the union. As a result, even when economies are hit by symmetric shocks (such as oil prices, world demand, and the euro exchange rate), the response of inflation will be different across countries. Depending on the interaction between wage and price dynamics, second round effects could make inflation even more persistent.

All these hypotheses have been useful to explain the individual inflation country experiences of EMU member countries, and are not mutually exclusive. Surprisingly, the existing literature lacks a methodology to test their relative importance in explaning overall inflation differentals. This paper estimates a two-country, twosector New Keynesian dynamic stochastic general equilibrium (DSGE) model of a currency union, using Spain and EMU data, and using Bayesian methods. ${ }^{3}$ A novel approach with respect to the existing literature that estimates DSGE models is that the model tries to explain the first moments of the data by having different trends in the country- and sector-specific technology shocks. Typically, the literature demeans or detrends the observable variables, and is concerned about fitting second moments of the data only. The main advantages of using a Bayesian approach are: first, information about the model's parameters can be introduced via the prior distribution. Second, from a computational point of view, it is helpful to identify the model's parameters (see Canova and Sala, 2006). This is particularly important in the present paper, because we use a relatively short sample that reflects the behavior of inflation and monetary policy under a currency area. Using a likelihood-based general equilibrium approach allows us to test all the implications of the model for explaining the data. Having specified a general equilibrium model with country- and sector-specific demand and productivity shocks, and with heterogeneous inflationary processes, we proceed to decompose the causes behind the inflation differentials between Spain and the EMU.

The results of the paper can be summarized as follows: first, the estimated degrees of nominal rigidity across countries and sectors are similar to those obtained with survey evidence, as summarized by Fabiani et al. (2006). Second, we find that the estimated coefficients that determine inflation dynamics in Spain and in the rest of the euro area are different. Third, our estimated impulse responses to tradable sector technology shocks suggest that the Balassa-Samuelson effect has not been

\footnotetext{
${ }^{3}$ See An and Schorfheide (2006) for a survey on the estimation of DSGE models using Bayesian methods.
} 
present during the EMU period. Finally, the most important explanation for the inflation differential between Spain and the euro area comes from tradable sector productivity shocks that affect either Spain, the rest of the euro area, or both. These explain about 50 percent of the variability of the inflation differential, while nontradable sector technology shocks explain about 25 percent of the inflation differential. Demand shocks are mostly useful to explain a significant fraction of output growth volatility, but only explain 25 percent of inflation dispersion.

The rest of the paper is organized as follows: in section 2 we present a decomposition of the inflation differential based on the tradable and nontradable components of the HICP. In section 3 we outline the model, while section 4 briefly describes the Bayesian econometric approach. In Section 5 we present the results in terms of posterior parameter distributions, impulse responses, and second moments. Section 6 concludes.

\section{Inflation Differentials between Spain and the EMU: What Drives Them?}

From the policy perspective, the question to ask is to what extent are these inflation differentials (and the associated real exchange rate changes) important. As we show in this section, the inflation differential between Spain and the euro area in the 20022006 period can be mostly explained by the behavior of the relative price of tradable goods: this represents a loss of competitiveness of the Spanish economy vis-à-vis its trading partners, that could potentially damage the prospects of growth.

However, real exchange rate and terms of trade (defined as the ratio of price of imports over price of exports) appreciation is indeed the expected mechanism through which adjustments would occur in a currency union. Large and persistent inflationary processes need not be "bad" per se, since countries growing above potential will have a tendency to have higher inflation, while countries in recession will tend to have lower inflation. As a result, countries in recession will experience a competitiveness gain, while those countries in the peak of their business cycle will suffer a loss: altogether, the effect will be to bring all countries in a monetary union back to potential. The important issue is to ensure that structural rigidites in the economy do not imply a too large imbalance build-up due to inflation persistence, and hence 
that the adjustment occurs smoothly, rather than resulting in a painful recession. ${ }^{4}$ The real exchange rate between Spain and the rest of the EMU can be expressed as

$$
R E R_{t}=\frac{P_{t}^{*}}{P_{t}}
$$

where $P_{t}^{*}$ is the price level of the rest of the EMU, and $P_{t}$ is the price level in Spain. We perform a simple decomposition of the real exchange rate (see Engel, 1999; Betts and Kehoe, 2006; and Chari et al. 2002). First, we multiply and divide the RER by the price of tradable goods in each country, such that we get:

$$
R E R_{t}=R E R_{t}^{T} * R E R_{t}^{R E L}
$$

where

$$
R E R_{t}^{T}=\frac{P_{t}^{T^{*}}}{P_{t}^{T}}, \text { and } R E R_{t}^{R E L}=\frac{\frac{P_{t}^{T}}{P_{t}}}{\frac{P_{t}^{T^{*}}}{P_{t}^{*}}} .
$$

Further, we can assume that in each country the CPI is a geometric average of tradable and nontradable goods, such that $P_{t}=\left(P_{t}^{T}\right)^{\gamma}\left(P_{t}^{N}\right)^{1-\gamma}, P_{t}^{*}=\left(P_{t}^{T^{*}}\right)^{\gamma^{*}}\left(P_{t}^{N^{*}}\right)^{1-\gamma^{*}}$, where $\gamma$ and $\gamma^{*}$ denote the fraction of tradable goods in each country's HICP, and $P_{t}^{T}, P_{t}^{N}, P_{t}^{T^{*}}, P_{t}^{N^{*}}$ are the prices of tradable $(\mathrm{T})$ and nontradable (N) goods in both countries. Then, the following expression holds for the change in the real exchange rate (lower case variables denote logs, and $\Delta$ is the difference operator):

$$
\begin{aligned}
\Delta \operatorname{rer}_{t}= & \Delta \operatorname{rer}_{t}^{T}+\Delta \operatorname{rer}_{t}^{R E L} \\
= & \Delta p_{t}^{T^{*}}-\Delta p_{t}^{T}+ \\
& +(1-\gamma)\left(\Delta p_{t}^{T}-\Delta p_{t}^{N}\right)-\left(1-\gamma^{*}\right)\left(\Delta p_{t}^{T^{*}}-\Delta p_{t}^{N^{*}}\right)
\end{aligned}
$$

Therefore, deviations from purchasing power parity can be explained by: (i) deviations from the law of one price for tradable goods, and (ii) movements of relative prices between tradable and nontradable goods inside each country. If the fraction of tradable goods in the CPI is the same across countries $\left(\gamma=\gamma^{*}\right)$, and the law of one price holds for tradable goods $\left(\Delta p_{t}^{T^{*}}=\Delta p_{t}^{T}\right)$ then fluctuations in the real exchange rate would be due to nontradable inflation only. ${ }^{5}$ If either the consumption basket differs across countries, or there are deviations from the law of one price, or both,

\footnotetext{
${ }^{4}$ See Blanchard (2006) and Roubini et al. (2007).

${ }^{5}$ This is the case analyzed by Altissimo et al. (2005).
} 


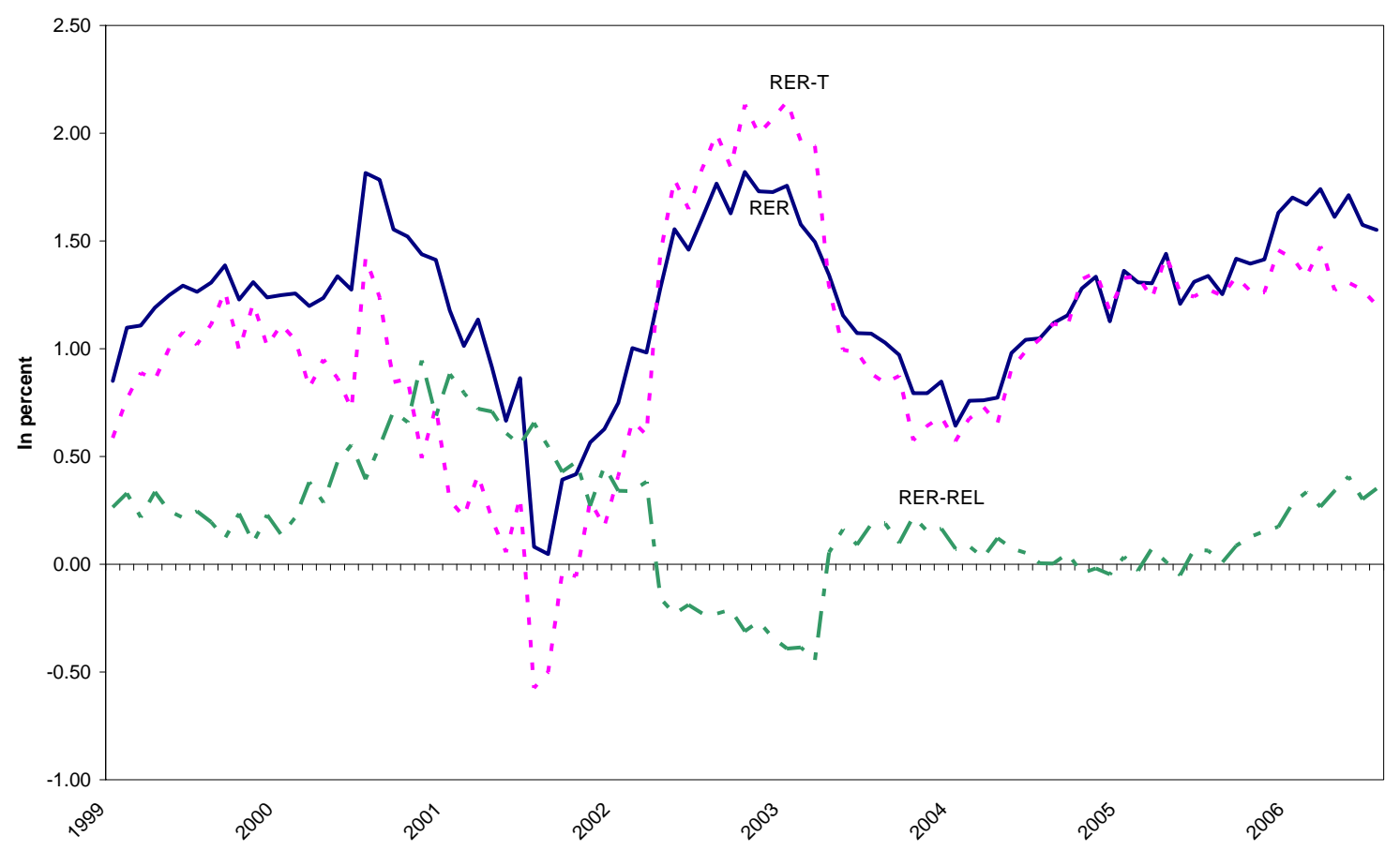

Figure 3: Decomposition of the inflation differential between tradable and nontradable inflation. Source: Eurostat and author's calculations.

then fluctuations in the price of tradable goods will also matter. As we show in the following figure, this is indeed the case for Spain.

Figure 3 presents this decomposition using year-on-year rates (12-month changes). This evidence is purely data-based, and does not rely on a specific functional form for price indices (arithmetic or geometric weighted averages), since by construction, $R E R_{t}^{R E L}=R E R_{t} / R E R_{t}^{T}$. Clearly, there are two important subperiods since the launch of the euro that help explain inflation differentials (by definition, the evolution of the change in the real exchange rate in a currency union is the inflation differential). In the 1999-2001 period, both the relative price of goods across countries, as well as the movements of relative prices of goods and services inside each country, seemed to play a role in explaning the inflation differential. However, since 2002 , virtually all the inflation differential can be explained by the evolution in the relative prices of tradable goods between Spain and the rest of the euro area. Tables 2 and 3 confirm this analysis by presenting sample means and correlation coefficients between these three components, for the full sample 1999-2006 and for the two-subsamples. For the full sample, we can observe that out of 1.2 percentage points of inflation differential between Spain and the euro area, 1 percentage 
point can be explained by the differential in the tradable goods component. This evidence is even more dramatic for the subsample period 2002-2006, where out of 1.28 percentage points of inflation differential, only 0.06 percentage points are due to the movement in relative prices across sectors in each country. In all cases, the correlation between the aggregate inflation differential and its tradable component is always positive and high, and the correlation is highest in the full sample period, with a value of 0.88 . On the contrary, the correlation between changes in the real exchange rate and the relative price component is mildly negative. ${ }^{6}$ Finally, the correlation between the tradable and the relative price component is negative and high in absolute value. ${ }^{7}$

Table 2: Sample Means

\begin{tabular}{lccc}
\hline & Full Sample & $1999-2001$ & $2002-2006$ \\
$\Delta \operatorname{rer}_{t}$ & 1.21 & 1.09 & 1.28 \\
$\Delta \operatorname{rer}_{t}^{T}$ & 1.01 & 0.65 & 1.22 \\
$\Delta \operatorname{rer}_{t}^{R E L}$ & 0.20 & 0.43 & 0.06 \\
\hline
\end{tabular}

Source: Eurostat and author's calculations.

Table 3: Correlation coefficients

\begin{tabular}{lccc}
\hline & Full Sample & $1999-2001$ & $2002-2006$ \\
$\Delta r e r_{t}, \Delta r e r_{t}^{T}$ & 0.86 & 0.88 & 0.88 \\
$\Delta r e r_{t}, \Delta r e r_{t}^{R E L}$ & -0.33 & -0.09 & -0.32 \\
$\Delta r e r_{t}^{T}, \Delta r e r_{t}^{R E L}$ & -0.76 & -0.54 & -0.73 \\
\hline
\end{tabular}

Source: Eurostat and author's calculations.

\footnotetext{
${ }^{6}$ This decomposition is done in terms of the overall real exchange rate, the traded goods real exchange rate, and the residual, and follows other papers in the literature. Another way to decompose the real exchange rate would have been to focus on the real exchange for nontraded goods $\left(R E R^{N}=P^{N *} / P^{N}\right)$, and a residual. In this case, the series $R E R$ and $R E R^{N}$ also display some strong comovement, but the evidence is not as strong as for the pair $\left(R E R, R E R^{T}\right)$. For the full sample, the correlation between $R E R$ and $R E R^{N}$ is 0.50 , while it increases to 0.67 for the 2002-2006 period. The inflation differential has a full sample mean of 1.63 percentage points, and a mean of 1.88 and 1.46 percentage points for the 1999-2001 and 2002-2006 sample periods respectively.

${ }^{7}$ Using a similar decomposition, Engel (1999) and Chari et al. (2002) found that most of the variability in the real exchange rate between the United States and main trading partners was due to traded goods. On the other hand, Betts and Kehoe (2006), and Burnstein et al. (2005) suggest that the using the "goods only" component of the CPI is not a good measure of the prices of traded goods, because they include distribution, marketing, and other services that are of a nontraded nature. Using different proxies for the price of traded and nontraded goods, both papers show that the latter can explain up to 50 percent of the variability in the real exchange rate. Proxies used include the PPI for industrial goods, gross output deflators, and import and export price deflators at the dock.
} 


\section{The Model}

In order to model the interactions between Spain and the rest of the Euro Area inside a currency union, and based on the evidence presented in Section 2, we construct and estimate a two-country New Keynesian Dynamic Stochastic General Equilibrium (DSGE) model of a currency union, similar to Duarte and Wolman (2002). ${ }^{8}$ To study the behavior of inflation, the model introduces nominal rigidities. To test for the presence and importance of the Balassa-Samuelson effect, the model includes tradable and nontradable goods in both countries, and productivity shocks that affect all countries and sectors. Productivity shocks have the effect of improving the production frontier for each type of good, and hence cause an increase of output and a decrease of prices in that sector. In addition to country-specific productivity shocks, the model incorporates productivity shocks at the euro area level that affect either the tradable sector, or both sectors (to allow for technology spillovers across countries in the union).

To understand the role of demand factors, the model incorporates demand shocks in the form of government spending in both tradable and nontradable goods. These shocks will tend to move output and prices of a given sector in the same direction, and hence are able to explain a different comovement than productivity shocks. To understand the role of monetary factors, the model incorporates a monetary policy shock which is the residual of a Taylor-type interest rate rule that targets the EMU HICP. Finally, the model allows for the possibility that the inflation dynamics equations across countries and sectors are different, and a formal test can be conducted to contrast this hypothesis. To match persistence in real variables, habit formation in consumption is introduced, as in Smets and Wouters (2003).

Finally, we discuss under which assumptions for the country- and sector-specific technology shock processes the model gives rise to permanent inflation differentals. In the empirical section of the paper, we estimate versions of the model where we try to fit the model-consistent real output growth and inflation first moments based on different growth rates of productivity. For comparison purposes with the exisitng practice in the literature, we also estimate one version of the model by simply demeaning the data and focusing on the business cycle properties on the model.

\footnotetext{
${ }^{8}$ Other DSGE-based explanations of inflation differentials using models with tradable and nontradable goods include Altissimo et al. (2005), and López-Salido et al. (2005).
} 


\subsection{Preferences}

We assume that there are two countries in the european monetary union, home $(H)$ and foreign $(F)$, of unequal size. The home country is of size $s$, while the foreign country is of size $1-s$. Brands of tradable goods are indexed by $h \in$ $[0, s]$ in the domestic country and by $f \in[s, 1]$ in the foreign country. Countries produce differentiated tradable goods that are imperfect substitutes of each other, but there is no price discrimination for the same type of good across countries. Brands of nontradable goods are indexed by $n \in[0, s]$ in the home country and by $n^{*} \in[s, 1] .{ }^{9}$ We assume that technology and preferences is the same accross countries, but countries differ in the composition of the consumption indices, and in the degrees of nominal rigidity. The preferences of typical household in the home country, indexed by $j \in[0, s]$ are assumed to be: ${ }^{10}$

$$
U_{t}=E_{0}\left\{\sum_{t=0}^{\infty} \beta^{t}\left[\log \left(C_{t}^{j}-b C_{t-1}\right)-\frac{\left(L_{t}^{j}\right)^{1+\varpi}}{1+\varpi}\right]\right\},
$$

where $E_{0}$ denotes the expectation conditional on the information set at date $t=$ 0 , and $\beta$ is the intertemporal discount factor, with $0<\beta<1$. $C_{t}^{j}$ denotes the level of consumption in period $t, L_{t}^{j}$ denotes labor supply. The utility function displays external habit formation, and depends on the home country's aggregate consumption. $b \in[0,1]$ denotes the importance of the habit stock, which is last period's aggregate consumption. $\varpi>0$ is inverse elasticity of labor supply with respect to the real wage.

We define the consumption index as a Cobb-Douglas aggregate of tradable and nontradable goods:

$$
C_{t}=\frac{\left(C_{t}^{T}\right)^{\gamma}\left(C_{t}^{N}\right)^{(1-\gamma)}}{\gamma^{\gamma}(1-\gamma)^{(1-\gamma)}}
$$

where $\gamma$ is the share of tradable goods in the consumption basket at home. A main

\footnotetext{
${ }^{9}$ The convention will be to use an asterisk to denote the counterpart in the foreign country of a variable in the home country (i.e. if aggregate consumption is $C$ in the home country, it will be $C^{*}$ in the foreign country and so on. The same applies to the model's parameters. When there is potential for confusion we try to explicitly clarifiy so. In what follows we only derive the optimizing conditions for home country agents. In an appendix available upon request we derive the full set of equilibrium conditions.

${ }^{10}$ Rabanal and Tuesta (2006) study real exchange rate dynamics in a two country model, and allow for different preference parameters across countries. As we explain below, our sample period is quite short, and to limit the number of parameters to be estimated it is useful to impose some symmetry restrictions.
} 
reason to use a Cobb-Douglas aggregator is that the shares of nominal spending on each type of good are constant, even when prices of different goods have different inflation rates.

The sub-index of consumption for tradable goods is defined as:

$$
C_{t}^{T}=\frac{\left(C_{t}^{H}\right)^{\lambda}\left(C_{t}^{F}\right)^{(1-\lambda)}}{\lambda^{\lambda}(1-\lambda)^{(1-\lambda)}}
$$

where $\lambda$ represents the degree of home bias in preferences. $C_{t}^{H}$ and $C_{t}^{F}$ are indexes of consumption across the continuum of differentiated goods produced in country $H$ and $F$, and are given by:

$$
C_{t}^{H} \equiv\left[\left(\frac{1}{s}\right)^{\frac{1}{\sigma}} \int_{0}^{s} c_{t}(h)^{\frac{\sigma-1}{\sigma}} d h\right]^{\frac{\sigma}{\sigma-1}}, C_{t}^{F} \equiv\left[\left(\frac{1}{1-s}\right)^{\frac{1}{\sigma}} \int_{s}^{1} c_{t}(f)^{\frac{\sigma-1}{\sigma}} d f\right]^{\frac{\sigma}{\sigma-1}}
$$

where $\sigma>1$ is the elasticity of substitution across goods produced within country $H$, denoted by $c_{t}(h)$, and country $F$, denoted by $c_{t}(f)$. Note that $C_{t}^{H}$ denotes consumption by home country nationals of domestically produced tradable goods, while $C_{t}^{F}$ denotes consumption by home country nationals of foreign country tradable goods. Similarly, the consumption of nontradables in the home country is given by

$$
C_{t}^{N} \equiv\left[\left(\frac{1}{s}\right)^{\frac{1}{\sigma}} \int_{0}^{s} c_{t}^{N}(n)^{\frac{\sigma-1}{\sigma}} d n\right]^{\frac{\sigma}{\sigma-1}}
$$

where $c_{t}^{N}(n)$ denotes the consumption of each individual nontradable good.

Individual demands for home and foreign tradables, and nontradable goods is given by:

$$
\begin{aligned}
c_{t}(h) & =\frac{\lambda \gamma}{s}\left(\frac{p_{t}(h)}{P_{t}^{H}}\right)^{-\sigma}\left(\frac{P_{t}^{H}}{P_{t}^{T}}\right)^{-1}\left(\frac{P_{t}^{T}}{P_{t}}\right)^{-1} C_{t}, \\
c_{t}(f) & =\frac{(1-\lambda) \gamma}{1-s}\left(\frac{p_{t}(f)}{P_{t}^{F}}\right)^{-\sigma}\left(\frac{P_{t}^{F}}{P_{t}^{T}}\right)^{-1}\left(\frac{P_{t}^{T}}{P_{t}}\right)^{-1} C_{t}, \text { and } \\
c_{t}^{N}(n) & =\frac{(1-\gamma)}{s}\left(\frac{p_{t}^{N}(n)}{P_{t}^{N}}\right)^{-\sigma}\left(\frac{P_{t}^{N}}{P_{t}}\right)^{-1} C_{t} .
\end{aligned}
$$

In this context, the home country consumer price index that corresponds to the 
previous specification is given by:

$$
P_{t}=\left(P_{t}^{T}\right)^{\gamma}\left(P_{t}^{N}\right)^{(1-\gamma)}
$$

where the home country price index for tradable goods has the following form:

$$
P_{t}^{T}=\left(P_{t}^{H}\right)^{\lambda}\left(P_{t}^{F}\right)^{(1-\lambda)}
$$

with prices of home and foreign tradable goods, and non-tradable goods defined, respectively as:

$$
\begin{aligned}
P_{t}^{H} & \equiv\left[\frac{1}{s} \int_{0}^{s} p_{t}(h)^{1-\sigma} d h\right]^{\frac{1}{1-\sigma}}, P_{t}^{F} \equiv\left[\frac{1}{1-s} \int_{s}^{1} p_{t}(f)^{1-\sigma} d f\right]^{\frac{1}{1-\sigma}}, \\
\text { and } P_{t}^{N} & \equiv\left[\frac{1}{s} \int_{0}^{s} p_{t}^{N}(n)^{1-\sigma} d n\right]^{\frac{1}{1-\sigma}},
\end{aligned}
$$

where $p_{t}(i)$ for $i=h, f$, and $p_{t}^{N}(n)$ are prices in the home country, for both tradable and nontradable goods, respectively. Prices for the foreign country $\left(P_{t}^{*}\right.$, and $P_{t}^{N^{*}}$ ) are analogously defined, where $\gamma^{*}$ is the fraction of tradable goods in the rest of the euro area consumption basket, and $\lambda^{*}$ is the fraction of foreign-produced goods in the foreign consumption aggregate (i.e. the foreign degree of home bias). The price indices $P_{t}^{H}$ and $P_{t}^{F}$ are the same across countries because there is no international price discrimination.

For modelling simplicity, we assume that there are complete markets at the national and euro area-wide levels. Households in both countries have access to a set of contigent bonds that pay one unit of currency in every possible state of nature in $t+1$. In order to keep notation simple we do not explicitly introduce the portfolio of statecontingent assets that allows households to insure them against idiosyncratic risk. We also assume that households have access to a riskless nominal bond denominated in euros (which, given the assumption of complete markets is redundant) that pays a gross rate of $R_{t}$. Then, the budget constraint of the domestic households in euros is given by:

$$
\frac{B_{t}}{P_{t} R_{t}} \leq \frac{B_{t-1}}{P_{t}}+W_{t} L_{t}-C_{t}+\Pi_{t}
$$

where $W_{t}$ is the real wage, and $\Pi_{t}$ are real profits for the home consumer.

The conditions characterizing the consumption/savings decisions is: 


$$
\begin{aligned}
\lambda_{t} & =\beta E_{t}\left\{\lambda_{t+1} \frac{R_{t} P_{t}}{P_{t+1}}\right\} \\
\lambda_{t} & =U_{C_{t}}
\end{aligned}
$$

where $U_{x}$ is the partial derivative of the utility function with respect to variable $x$. Equation (10) corresponds to the consumption Euler equation of the home consumer. The first order conditions with respect to the labor supply implies the usual condition that:

$$
-U_{L_{t}}=\lambda_{t} W_{t}
$$

where total labor is allocated between tradable and nontradable activities:

$$
L_{t}=L_{t}^{T}+L_{t}^{N}
$$

while combining optimality conditions between home and foreign households delivers the following condition for the real exchange rate, under complete markets, and the same initial conditions across countries:

$$
R E R_{t}=\frac{P_{t}^{*}}{P_{t}}=\frac{\lambda_{t}^{*}}{\lambda_{t}}
$$

\subsection{The Government}

In both countries, the government demands domestically produced tradable and nontradable goods. The demand of the government has the same elasticties as the demand of the private sector:

$$
\begin{aligned}
& g_{t}(h)=\frac{\lambda \gamma}{s}\left(\frac{p_{t}(h)}{P_{t}^{H}}\right)^{-\sigma}\left(\frac{P_{t}^{H}}{P_{t}^{T}}\right)^{-\theta} G_{t}^{T}, \\
& g_{t}(n)=\frac{(1-\gamma)}{s}\left(\frac{p_{t}^{N}(n)}{P_{t}^{N}}\right)^{-\sigma} G_{t}^{N} .
\end{aligned}
$$

where $G_{t}^{T}$ and $G_{t}^{N}$ are exogenous process. 


\subsection{Price Setting and Technology}

In this model, suppliers behave as competitive monopolists when selling their products, subject to a Calvo-type restriction. In every period, intermediate goods producers receive a stochastic signal that allows them to change prices. This signal arrives with probability $1-\theta_{N}$ in the non-tradable sector, and $1-\theta_{H}$ in the tradable sector. In addition, we assume that when firms are not allowed to reoptimize, a fraction $\varphi_{N}$ indexes its price to last period's inflation rate in the nontradable sector, while a fraction $1-\varphi_{N}$ indexes its price to the sector's steady-state rate of inflation (the analogous coefficients in the tradable sector are $\varphi_{H}$ and $\left.1-\varphi_{H}\right) .{ }^{11}$

The model includes a euro-area technology shock with a unit root, that gives growth to the model. An advantage of this approach is that real variables in the model and in the data will be nonstationary in levels, but stationary in first differences, and hence provides a model-based method to detrend the data. The model also includes technology shocks that may include different trends in the tradable and nontradable sectors for each country, and can give rise to permanent inflation differentials across countries and sectors. Finally, we assume that the innovations to the tradable sector technology shock are correlated across countries.

\subsubsection{Non-Tradable Sector}

Each firm produces according to the following production function

$$
y_{t}^{N}(n)=Z_{t}^{N} L_{t}^{N}(n) X_{t}
$$

where $X_{t}$ is a labor augmenting aggregate euro-area wide technology shock which has a trend:

$$
X_{t}=(1+x)^{t} \exp \left(\varepsilon_{t}^{x}\right)
$$

and $\varepsilon_{t}^{x}$ is an iid shock. $Z_{t}^{N}$ is the country-specific productivity shock to the nontradable sector at time $t$. We discuss below how the properties of the country-sector specific shocks can generate persistent inflation differentials in the model.

\footnotetext{
${ }^{11}$ Allowing for partial indexation in the steady state gives rise to inefficient dispersion of prices, as well as steady-state effects of a positive inflation rate. See Schmitt-Grohé and Uribe (2006).
} 
Firms in the non-tradable sector face the following maximization problem:

$$
\operatorname{Max}_{p_{t}^{N}(n)} E_{t} \sum_{k=0}^{\infty} \theta_{N}^{k} \Lambda_{t, t+k}\left\{\left[\frac{p_{t}^{N}(n)\left(\frac{P_{t+k-1}^{N}}{P_{t-1}^{N}}\right)^{\varphi_{N}}\left(\Pi^{N}\right)^{k\left(1-\varphi_{N}\right)}-M C_{t+k}^{N}}{P_{t+k}}\right] y_{t+k}^{N, d}(n)\right\}
$$

subject to

$$
y_{t+k}^{N, d}(n)=\frac{(1-\gamma)}{s}\left(\frac{p_{t}^{N}(n)}{P_{t+k}^{N}}\left(\frac{P_{t+k-1}^{N}}{P_{t-1}^{N}}\right)^{\varphi_{N}}\left(\Pi^{N}\right)^{k\left(1-\varphi_{N}\right)}\right)^{-\sigma} Y_{t+k}^{N}
$$

where $\Lambda_{t, t+k}=\beta^{k} \frac{\lambda_{t+k}}{\lambda_{t}}$ is the stochastic discount factor, $y_{t}^{N, d}(n)$ is total individual demand for a given type of nontradable good, and $Y_{t}^{N}$ is aggregate demand for nontradable goods, consisting of private consumption and government spending:

$$
Y_{t}^{N}=C_{t}^{N}+G_{t}^{N}
$$

$M C_{t}^{N}$ corresponds to the nominal marginal cost in the non-tradable sector. From cost minimization:

$$
M C_{t}^{N}=P_{t} \frac{W_{t}}{Z_{t}^{N} X_{t}}
$$

The supplier maximizes (16) with respect to $p_{t}^{N}(n)$ given the demand function (17) and taking as given the sequences of all other prices. The optimal choice in the symmetric equilibrium is given by:

$$
\frac{\hat{p}_{t}^{N}}{P_{t}^{N}}=\frac{\sigma}{(\sigma-1)} E_{t}\left\{\frac{\sum_{k=0}^{\infty} \beta^{k} \theta_{N}^{k} \lambda_{t+k}\left(\prod_{s=1}^{k} \frac{\left(\Pi_{t+s-1}^{N}\right)^{\varphi_{N}}\left(\Pi^{N}\right)^{s\left(1-\varphi_{N}\right)}}{\Pi_{t+s}^{N}}\right)^{-\sigma} \frac{M C_{t+k}^{N}}{P_{t+k}^{N}} Y_{t+k}^{N}}{\sum_{k=0}^{\infty} \beta^{k} \theta_{N}^{k} \lambda_{t+k}\left(\prod_{s=1}^{k} \frac{\left(\Pi_{t+s-1}^{N}\right)^{\varphi_{N}}\left(\Pi^{N}\right)^{s\left(1-\varphi_{N}\right)}}{\Pi_{t+s}^{N}}\right)^{1-\sigma} Y_{t+k}^{N}}\right\}
$$

The evolution of the price level of non-tradables is

$$
P_{t}^{N} \equiv\left\{\theta_{N}\left[P_{t-1}^{N}\left(\Pi_{t-1}^{N}\right)^{\varphi_{N}}\left(\Pi^{N}\right)^{\left(1-\varphi_{N}\right)}\right]^{1-\sigma}+\left(1-\theta_{N}\right)\left(\hat{p}_{t}^{N}\right)^{1-\sigma}\right\}^{\frac{1}{1-\sigma}}
$$

where $\Pi_{t-1}^{N}=\frac{P_{t-1}^{N}}{P_{t-2}^{N}}$. 


\subsubsection{Tradable Sector}

Most expressions in the tradable sector are analogous to those of the nontradable sector. Each firm produces according to the following production function

$$
y_{t}^{H}(h)=Z_{t}^{T} L_{t}^{T}(h) X_{t}
$$

$Z_{t}^{T}$ is the country-specific productivity shock to the tradable sector at time $t$, whose properties we examine below. Firms cannot price-discriminate in the currency area, and set the price in euros to sell in both markets, facing a downward sloping demand. Proceeding the same way as with the nontradable sector, we arrive at the following optimal expressions:

$$
\frac{\hat{p}_{t}^{H}}{P_{t}^{H}}=\frac{\sigma}{(\sigma-1)} E_{t}\left\{\frac{\sum_{k=0}^{\infty} \beta^{k} \theta_{H}^{k} \lambda_{t+k}\left(\prod_{s=1}^{k} \frac{\left(\Pi_{t+s-1}^{H}\right)^{\varphi_{H}}\left(\Pi^{H}\right)^{s\left(1-\varphi_{H}\right)}}{\Pi_{t+s}^{H}}\right)^{-\sigma} \frac{M C_{t+k}^{H}}{P_{t+k}^{H}} Y_{t+k}^{H}}{\sum_{k=0}^{\infty} \beta^{k} \theta_{H}^{k} \lambda_{t+k}\left(\prod_{s=1}^{k} \frac{\left(\Pi_{t+s-1}^{H}\right)^{\varphi_{H}}\left(\Pi^{H}\right)^{s\left(1-\varphi_{H}\right)}}{\Pi_{t+s}^{H}}\right)^{1-\sigma} Y_{t+k}^{H}}\right\}
$$

where

$$
M C_{t}^{H}=P_{t} \frac{W_{t}}{Z_{t}^{H} X_{t}}
$$

The evolution of the price level of tradables is

$$
P_{t}^{H} \equiv\left\{\theta_{H}\left[P_{t-1}^{H}\left(\Pi_{t-1}^{H}\right)^{\varphi_{H}}\left(\Pi^{H}\right)^{\left(1-\varphi_{H}\right)}\right]^{1-\sigma}+\left(1-\theta_{H}\right)\left(\hat{p}_{t}^{H}\right)^{1-\sigma}\right\}^{\frac{1}{1-\sigma}}
$$

where $\Pi_{t-1}^{H}=\frac{P_{t-1}^{H}}{P_{t-2}^{H}}$.

\subsection{Monetary Policy}

In order to abstract from fiscal policy considerations, it is assumed that government spending in the two areas is financed through lump sum taxes. Monetary policy is conducted by the ECB with a Taylor rule that only targets the EMU HICP:

$$
R_{t}=\bar{R}^{1-\rho_{r}} R_{t-1}^{\rho_{r}}\left(\frac{\Pi_{t}^{E M U}}{\bar{\Pi}^{E M U}}\right)^{\left(1-\rho_{r}\right) \gamma_{\pi}} \exp \left(\varepsilon_{t}^{m}\right)
$$


where $\varepsilon_{t}^{m}$ is an iid monetary policy shock. The gross inflation rate is given by $\Pi_{t}^{E M U}=\frac{P_{t}^{E M U}}{P_{t-1}^{E M U}}$, where the European HICP is defined as

$$
P_{t}^{E M U}=P_{t}^{s}\left(P_{t}^{*}\right)^{1-s}
$$

where $s$ is the size of the home economy.

\subsection{Market Clearing}

The market clearing condition in the tradable goods sector at home is

$$
y_{t}^{H}(h)=c_{t}(h)+c_{t}^{*}(h)+g_{t}(h), \text { for } \forall h \in[0, s]
$$

The market clearing for the nontradable goods sector is

$$
y_{t}^{N}(n)=c_{t}(n)+g_{t}(n), \text { for } \forall n \in[0, s]
$$

In the aggregate the following conditions hold:

$$
\begin{gathered}
Y_{t}^{H}=C_{t}^{H}+C_{t}^{H^{*}}+G_{t}^{T} \\
Y_{t}^{N}=C_{t}^{N}+G_{t}^{N}
\end{gathered}
$$

Aggregate real GDP aggregates tradable and nontradable goods using the appropiate relative prices:

$$
Y_{t}=\frac{P_{t}^{H}}{P_{t}} Y_{t}^{H}+\frac{P_{t}^{N}}{P_{t}} Y_{t}^{N}
$$

\subsection{Technology Shocks and the Persistence of Inflation Dif- ferentials}

In this paper we take a novel approach with respect to the existing literature on estimating DSGE models and study the differences in inflation means across countries and sectors. In the literature that estimates DSGE models with likelihood-based methods, it is customary to demean (or HP-filter) the observed variables used for estimation (such as inflation, output growth, nominal interest rates and so on) and 
focus on how well these models can explain business cycle properties of the data. ${ }^{12}$ Here, we ask how well can the model reproduce first and second moments of the data.

Combining optimal price setting conditions across sectors in the steady-state, it can be shown that the following ratio holds: ${ }^{13}$

$$
\frac{Z^{T}}{Z^{N}} \frac{P^{H}}{P^{N}}=1
$$

Therefore, it is possible to have different inflation rates across sectors and countries in the model if the levels of technology grow at different rates. Hence, we study different possibilities for technology shocks in this paper.

The first specification we focus on consists in assuming different growth rates of productivity across sectors and countries, coming from technology shocks that have a trend component and a stationary component. The nontradable technology shock at home evolves as follows:

$$
\begin{aligned}
Z_{t}^{N} & =\left(1+\alpha^{N}\right)^{t} \hat{Z}_{t}^{N} \\
\log \left(\hat{Z}_{t}^{N}\right) & =\rho^{Z, N} \log \left(\hat{Z}_{t-1}^{N}\right)+\varepsilon_{t}^{Z, N}
\end{aligned}
$$

while the tradable technology technology shock is:

$$
\begin{aligned}
Z_{t}^{T} & =\left(1+\alpha^{T}\right)^{t} \hat{Z}_{t}^{T} \\
\log \left(\hat{Z}_{t}^{T}\right) & =\rho^{Z, T} \log \left(\hat{Z}_{t-1}^{T}\right)+\varepsilon_{t}^{Z, T}+\varepsilon_{t}^{Z}
\end{aligned}
$$

As a result, inflation differentials are permanent in the model when $\alpha^{N} \neq \alpha^{T}$, but an appropiate normalization of the price levels and real variables, each one growing at a different rate, makes these variables stationary in the model.

The productivity shocks in the two sectors are different in two important aspects. First, the growth rates can be different. Second, the tradable sector shock has a country-specific innovation component, $\varepsilon_{t}^{Z, T}$, and a euro-area innovation component, $\varepsilon_{t}^{Z}$. As long as the standard deviation of $\varepsilon_{t}^{Z}$ is positive, there will be some correlation in the tradable sector productivity shocks, as in most of the International Real Business Cycle literature (see Stockman and Tesar, 1995; and Baxter and Crucini,

\footnotetext{
${ }^{12}$ See Smets and Wouters (2003), Lubik and Schorfheide (2004), and Rabanal and Rubio-Ramírez (2005) among many others.

${ }^{13}$ See the Appendix for details.
} 
1993). The growth rates of the productivity shocks will be estimated to match inflation differentials across countries and sectors.

It is worth noting that this type of shock process imposes restrictions on the first moments of the growth rates of the variables in the model, and hence on the vector of constants in the steady-state representation of the model. For instance, the demand for nontradable goods is:

$$
C_{t}^{N}=(1-\gamma)\left(\frac{P_{t}^{N}}{P_{t}}\right)^{-1} C_{t}
$$

which implies that aggregate nominal spending $P_{t} C_{t}$ and nontradable nominal spending $P_{t}^{N} C_{t}^{N}$ grow at the same rate. In order to have higher inflation in nontradables (i.e. $P_{t}^{N}$ grows faster than $P_{t}$ ), it must be the case that $C_{t}^{N}$ grows slower than $C_{t}$ by the exact same rate. Hence, if in our sample period both prices and real variables grow faster in a sector than in another, this restriction will pose problems to fit the data.

The second specification that we examine is that the country- and sector-specific technology shocks are stationary and do not have a trend (i.e. $\alpha^{N}=\alpha^{T}=\alpha^{N^{*}}=$ $\alpha^{T^{*}}=0$ ). Hence, inflation could be non-zero in the steady-state, but it is the same in all sectors. In the same vein, under this specification, real growth is $x$ in all sectors (the aggregate technology shock is still assumed to grow with a trend). This assumption imposes a different set of restrictions on the vector of constants in the state-space representation of the model.

Finally, the third specification we estimate is the model with stationary technology shocks and no trends (again, all $\alpha$ 's are equal to zero) and with an unrestricted vector of constants. Therefore, we remove the restrictions on the model being able to match the first moments of the data. This procedure is equivalent to estimating the model after demeaning the data, which is the usual, but not necessarily model-consistent way, of proceeding.

In all cases, the model's dynamics are obtained by taking a linear approximation around the balanced growth path with positive (and different) rates of real growth and inflation, as in King, Plosser and Rebelo (1988). Price levels and real variables are normalized accordingly to make them stationary. ${ }^{14}$

\footnotetext{
${ }^{14}$ An Appendix available upon request details how to detrend each variable and take a linear approximation of the model.
} 


\section{Parameter Estimation}

The goal of this paper is to estimate the parameters of the two-country, two-sector model using data for Spain and the euro area, and using Bayesian methods. In this section we briefly sketch how to make the Bayesian estimation method operational. Denote by $\left\{\chi_{t}\right\}_{t=1}^{T}$ the set of observable variables that we wish to explain, and $\Theta$ the vector of parameters of the model (including preferences, technology, government policies, and stochastic properties of the shocks). From Bayes rule, the posterior distribution of the model's parameters is proportional to the product of the likelihood function $\mathfrak{L}\left(\left\{\chi_{t}\right\}_{t=1}^{T} \mid \Theta\right)$ and the prior distribution $\Upsilon(\Theta)$ :

$$
P\left(\Theta \mid\left\{\chi_{t}\right\}_{t=1}^{T}\right) \propto \Upsilon(\Theta) \mathfrak{L}\left(\left\{\chi_{t}\right\}_{t=1}^{T} \mid \Theta\right)
$$

Prior information about the model's parameters is introduced in the $\Upsilon($.) function. In order to evaluate the likelihood function, denote by $S_{t}$ the set of all endogenous variables of the model (either state or forward looking, observable or not, expressed in log-deviations from steady-state values, and hence with zero mean), and by $\Psi_{t}$ the set of all shocks. The linearized system with rational expectations is solved with standard methods, and the law of motion of the model can be written as:

$$
\begin{aligned}
S_{t} & =A(\Theta) S_{t-1}+B(\Theta) \Psi_{t} \\
\Psi_{t} & =C(\Theta) \Psi_{t-1}+D(\Theta) \varepsilon_{t}
\end{aligned}
$$

where $E\left(\varepsilon_{t} \varepsilon_{t}^{\prime}\right)=I, \varepsilon_{t}$ is the vector of structural innovations, and the matrices $A, B, C, D$ are functions of the parameters of the model, $\Theta$. We complement the law of motion of the model with a measurement equation:

$$
\chi_{t}=\kappa(\Theta)+H S_{t}
$$

where the $H$ has zeros everywhere, and a one in each row to select a subset of observable variables from $S_{t}$, and the vector of constants $\kappa$ depends on parameters of the model. The system of equations (26)-(27) is the usual state-space representation of a model, with the first set of equations being the transition equation, and the second equation being the measurement equation. Then, for a given vector of parameters $\Theta$, the likelihood function can be evaluated applying standard Kalman filter formulas. 
The prior might involve non-normal distributions, and the likelihood function does not have a closed-form expression. As a result, it is not possible to obtain an analytical expression for the posterior. Since we are able to numerically evaluate the prior and the likelihood function, then it is possible to numerically construct the posterior distribution of the model's parameters by making use of Markov Chain Monte Carlo (MCMC) methods. ${ }^{15}$ Basically, they amount to efficiently draw from the posterior distribution, and obtain a time series of $\Theta$, from which we can compute the posterior moments of the model's parameters, as well as posterior impulse responses and second moments. In our case, we make use of the Metropolis-Hastings algorithm and obtain 125,000 draws, after allowing for a burn-in phase of 25,000 draws.

\subsection{Data}

\subsubsection{Choice of Sample Period}

We face severe data restrictions when estimating the model using Euro Area data. The euro and the common monetary policy were launched in January 1st, 1999, and this paper attempts to study the behavior of inflation in a currency union. At a quarterly frequency, the sample would consist of 32 observations, which represent too few observations, given that the model has a fair amount of parameters. For asymptotic reasons, it is desirable to have the longest possible time series, and several papers have used the Area Wide Model (AWM) data set of Fagan, Henry and Mestre (2001) to estimate models of the Euro Area as a whole. ${ }^{16}$ By making this choice, one implicitly assumes that the Euro Area behaved like a common currency area since the beginning of the sample period (the 1970s, or the 1980s). This can be a difficult assumption to accept, specially for those countries who joined the European Union (EU) and the European Monetary System (EMS) over the years. The assumption of a common monetary policy might be a good approximation for the countries in the "core" of the old EMS. For instance, Pytlarczyk (2005), estimates a model of Germany inside the euro area using data from 1980. But Spain has suffered many changes in monetary policy regimes: it joined the EU in 1986, and the EMS in 1989, and launched inflation targeting in 1995 to converge in nominal terms with the rest of countries of the euro area. All these changes are likely to result in changes in the

\footnotetext{
${ }^{15}$ See An and Schorfheide (2006) for a description.

${ }^{16}$ This is a synthetic, nonofficial dataset maintained at the Econometric Modelling Unit of the ECB. For two examples, see Smets and Wouters (2003), and Rabanal and Tuesta (2006).
} 


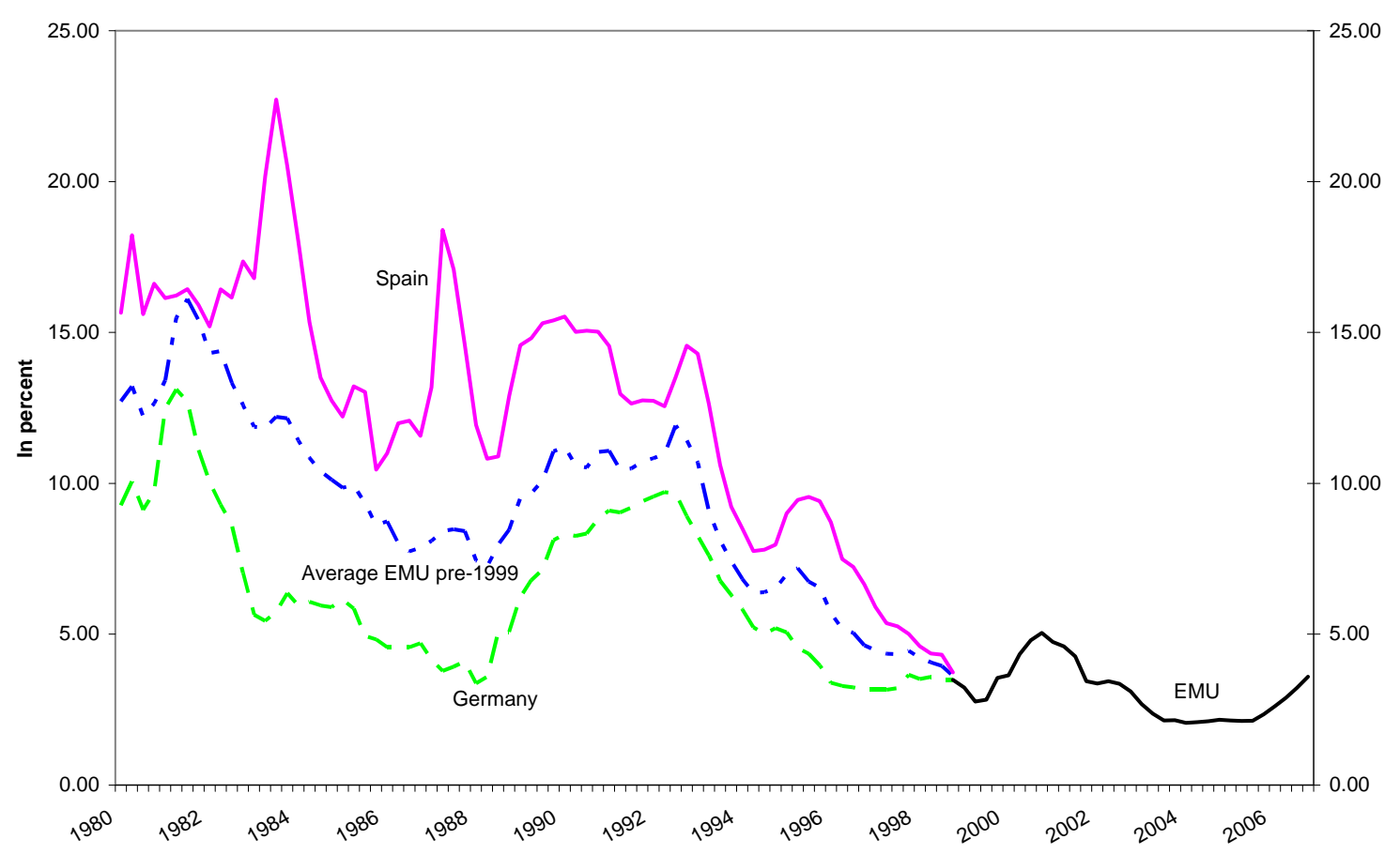

Figure 4: Interest Rates, 3 Month Treasury Bills. Source: Eurostat and ECB.

behavior of agents, and parameter instability.

Figure 4 presents the 3-month T-bill rate in Spain, Germany, an average of the euro area before 1999, and the euro area 3-month T-bill after 1999. Monetary policy in Spain did not follow that of the Bundesbank or a european aggregate during the 1980s and even most of the 1990s. Convergence in interest rates happened after 1997: the spread between Spain's 3-month rates and the average of the Euro area became less than 50 basis points in the last 20 years only after the fourth quarter of 1997.

Finally, Figure 5 shows the annual CPI inflation rate. For the whole sample period, and specially in the 1980s and early 1990s Spain experienced higher inflation than the euro area. Focusing on more recent periods, average inflation in the euro area countries crossed the 4 percent threshold in 1992:03, and has stayed below that value ever since. In Spain, it took three and a half more years for inflation to fall under 4 percent (in 1996:01), after more than two decades of higher inflation rates.

For all the reasons we have explained in this subsection, and to address the fact that there was a structural change in Spain in the process of converging in nominal terms to the Euro Area, we start our sample period in 1996:01. This leaves our sample 


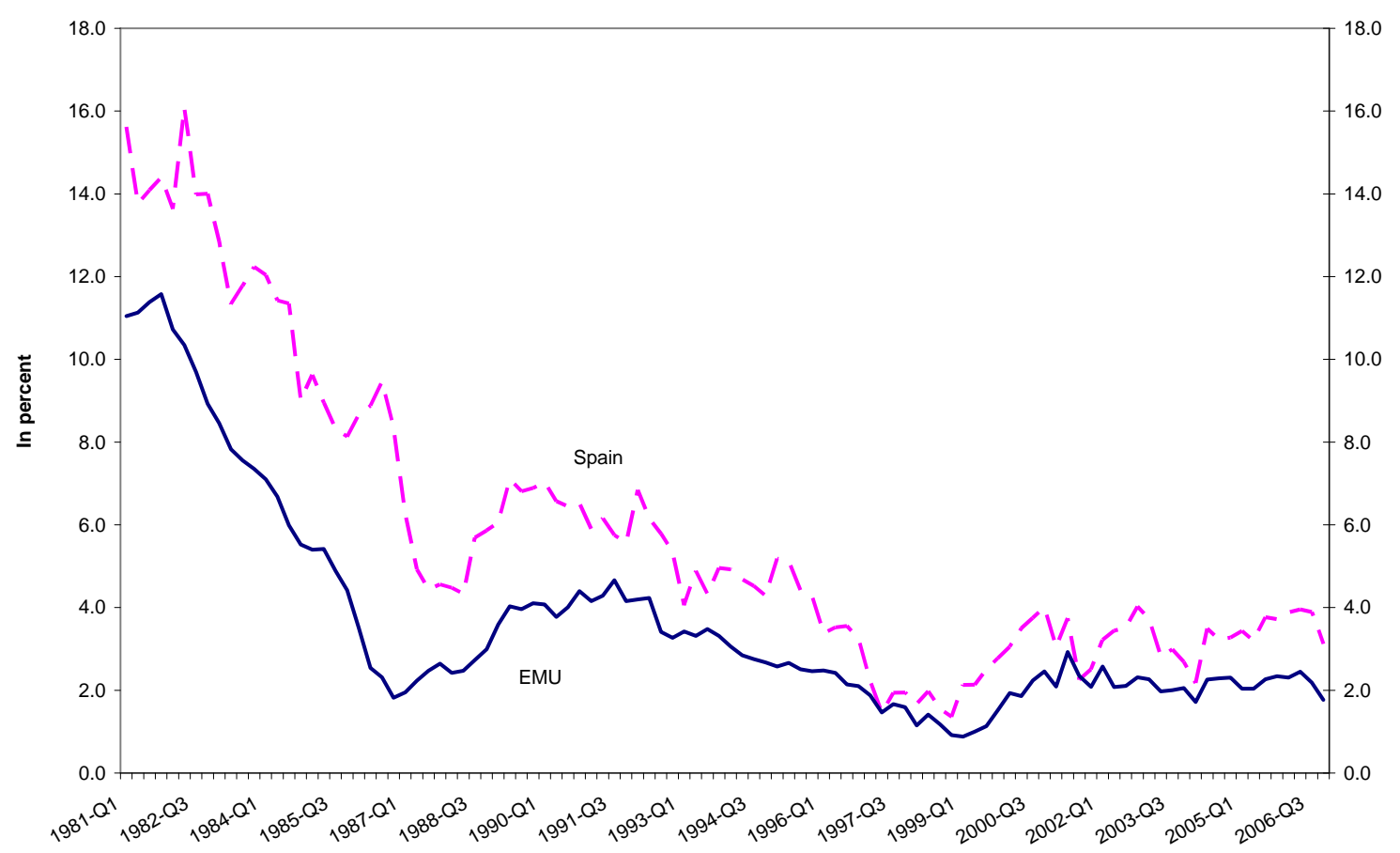

Figure 5: CPI Inflation Rates. Source: Eurostat.

with 44 observations. Clearly, this is a short sample, and only with time we will be able to estimate this model with more observations from the EMU period.

\subsubsection{Variables}

The model presented in Section 3 is estimated with eight variables. These variables are quarterly HICP inflation, quarterly HICP Services inflation, quarterly real GDP growth rates for both Spain and EMU, quarterly nontradable (Services and Construction) real GDP growth for Spain, and the 3-month T-bill rate (between 1996-1998, we use an average of the euro area's 3-month t-bill). ${ }^{17}$ We take logs and first differences of the real GDP and price level series to obtain quarterly growth rates. We divide the interest rate by four hundred to obtain a quarterly equivalent. The home country is Spain and the foreign country is the rest of the euro area.

As we mentioned in the previous section, we estimate the model in three different ways, which mainly affect the vector of constants in the state-space representation

\footnotetext{
${ }^{17}$ All EMU data come from Eurostat, as well as Spain's HICP and its services components. Spain's sectoral GDP data come from the Instituto Nacional de Estadística (INE, National Statistics Institute).
} 
of the model. Denote by $\chi_{t}=\left\{\Delta p_{t}, \Delta p_{t}^{E M U}, \Delta p_{t}^{N}, \Delta p_{t}^{N, E M U}, \Delta y_{t}, \Delta y_{t}^{E M U}, \Delta y_{t}^{N}\right.$, $\left.r_{t}\right\}$ the vector of observable variables. Under the first specification for technology shocks discussed in the previous section, the vector of constants is given by:

$\kappa_{1}=\left\{\log (\Pi), \log \left(\Pi^{E M U}\right), \log \left(\Pi^{N}\right), \log \left(\Pi^{N, E M U}\right), \Delta y, \Delta y^{E M U}, \Delta y^{N}, \log \left[\frac{(1+x) \Pi^{E M U}}{\beta}\right]\right\}$

where $\Delta y^{E M U}=x, \Delta y=x+\log \left(\Pi^{E M U}\right)-\log (\Pi)$, and $\Delta y^{N}=x+\log \left(\Pi^{E M U}\right)-$ $\log \left(\Pi^{N}\right)$. We select the growth rates of sector- and country-specific technology shocks to exactly match the sample mean of inflation rates, and the growth rate of $x$ to match the growth rate of euro area real GDP. This imposes a restriction on the growth rates of aggregate and nontradable real GDP growth in Spain. Note also that we are imposing the mean of the nominal interest rate.

Under the second specification, the vector of constants is given by:

$$
\kappa_{2}=\left\{\log \left(\Pi^{E M U}\right), \log \left(\Pi^{E M U}\right), \log \left(\Pi^{E M U}\right), \log \left(\Pi^{N, E M U}\right), x, x, x, \log \left[\frac{(1+x) \Pi^{E M U}}{\beta}\right]\right\}
$$

where $\Pi^{E M U}$ is the common inflation rate to all sectors. Under this hypothesis, all real and nominal variables grow at the same rates, but different realizations of the shocks during this period have implied different sample real growth and inflation rates.

In the third case, we use an unrestricted vector of constants $\kappa_{3}$. In practice, we use the sample mean of each variable and hence the estimation is equivalent to demeaning the data. The differences between $\kappa_{2}$ and $\kappa_{3}$ are not only that the latter can fit all sample real growth and inflation mean rates better, but also the mean of the nominal interest rate.

\subsubsection{Priors}

Since our sample is short, we opt for calibrating most of the parameters of the model $(\Theta)$, and focus on estimating the coefficients of the Taylor rule, the degrees of nominal rigidity in each sector and country, and the autoregressive parameters and standard deviations of the shocks. In order to further reduce the number of parameters to be estimated, we assume that the AR coefficients of the shocks are the same for each type of shock. Table 4 presents the parameter values that we 
calibrate, and the sources that we use.

The steady state nominal interest rate is $\log \left[\frac{(1+x) \Pi^{E M U}}{\beta}\right]$. As Ireland (2004) points out, in models where technology follows a unit root with drift, it is difficult to find reasonable calibrations for the three parameters $\left(x, \Pi^{E M U}, \beta\right)$ that deliver at the same time a reasonable steady-state value for the nominal interest rate. For instance, if we assume that both the real growth rate and the inflation rate are 2 per cent annual rate, this is enough to make the interest rate 4 percent annual rate in the steady state, which is slightly above what we observe in the data for the recent years. Hence, we need calibrations of $\beta$ very close to one. To keep the problem of the consumer bounded, we calibrate $\beta$ to 0.999 .

For the parameters involving bilateral trade $\left(\lambda, \lambda^{*}\right)$, government spending $\left(\eta, \eta^{*}\right)$ or the size of sectors $\left(\gamma, \gamma^{*}\right)$, we use national accounts data and Eurostat. For the size of the Spanish economy inside the EMU HICP $(s)$, we calibrate this parameter such that the trade balance is zero in steady state. Luckily, the number is very close (0.10 versus 0.11 ) to the average weight for the sample period (weights are revised every year). Then, we calibrate the parameters denoting habit formation $\left(b, b^{*}\right)$, the inverse elasticity of labor supply $\left(\varpi, \varpi^{*}\right)$. We are aware that the choice of the calibrated parameters affects the estimated ones. As more data become available, we would like to be able to estimate these as well. Finally, we calibrate the growth rates of sector-specific technology shocks to match the sample mean of the four inflation indicators we use. 
Table 4: Calibrated Parameters

\begin{tabular}{lll}
\hline Parameter & Value & Source \\
\hline$\beta$ & 0.999 & \\
$\varpi, \varpi^{*}$ & 1 & Rabanal and Rubio-Ramírez (2005) \\
$b, b^{*}$ & 0.6 & Rabanal and Tuesta $(2006)$ \\
$s$ & 0.11 & Average weight of Spain HCPI in EMU HCPI since 1996 \\
$x$ & 0.006 & Quarterly average real GDP Growth Euro Area since 1996 \\
$\Pi^{E M U}$ & 1.0047 & Quarterly average EMU HICP Inflation since 1996 \\
$\Pi^{N, E M U}$ & 1.0071 & Quarterly average Spain HICP Inflation since 1996 \\
$\Pi^{N}$ & 1.0055 & Quarterly average EMU Services HICP Inflation since 1996 \\
$\eta$ & 1.0092 & Quarterly average Spain Services HICP Inflation since 1996 \\
$\eta^{*}$ & 0.18 & Average ratio G/Y in Spain since 1996 \\
$\gamma$ & 0.20 & Average ratio G/Y in Euro Area since 1996 \\
$\gamma^{*}$ & 0.66 & Proportion of goods in Spain HCPI \\
$\lambda$ & 0.61 & Proportion of goods in Euro Area HCPI \\
$\lambda^{*}$ & 0.16 & Average ratio of imports from EMU over total spending \\
\hline
\end{tabular}

Table 5: Priors

\begin{tabular}{llcc}
\hline Parameter & Distribution & Mean & Std. Dev. \\
\hline$\theta_{N}, \theta_{H}, \theta_{N^{*}}, \theta_{F^{*}}$ & Beta & 0.75 & 0.15 \\
$\varphi_{N}, \varphi_{H}, \varphi_{N^{*}}, \varphi_{F^{*}}$ & Beta & 0.6 & 0.2 \\
$\gamma_{\Pi}$ & Normal & 1.5 & 0.1 \\
$\rho_{R}$ & Beta & 0.7 & 0.1 \\
$\rho^{Z, N}, \rho^{Z, T}, \rho^{G, N}, \rho^{G, T}$, & Beta & 0.7 & 0.1 \\
$\sigma\left(\varepsilon_{t}^{X}\right), \sigma\left(\varepsilon_{t}^{Z}\right)$ & Gamma & 0.7 & 0.3 \\
$\sigma\left(\varepsilon_{t}^{Z, i}\right), i=N, T, N^{*}, T^{*}$ & Gamma & 0.7 & 0.3 \\
$\sigma\left(\varepsilon_{t}^{G, i}\right), i=N, T, N^{*}, T^{*}$ & Gamma & 1 & 0.5 \\
$\sigma\left(\varepsilon_{t}^{m}\right)$ & Gamma & 0.4 & 0.2 \\
\hline
\end{tabular}

Table 5 displays the prior distributions over the estimated parameters. We assume that all Calvo lotteries have a prior mean probability of 0.75 , implying that prices are reset optimally every 4 quarters. These values are in line with the survey evidence 
in Fabiani et al. (2006). The degree of indexation has a prior mean of 0.6, which is somewhat larger than the survey evidence presented in Fabiani et al. (2006), but tries to reflect the fact that inflation differentials are highly persistent. At any rate, the standard deviation is large enough to accomodate a wide enough range of parameter values. The Taylor rule coefficients have prior means which are quite conventional in the literature, the reaction to inflation respects the Taylor principle, and we restrict the parameters of the model to the region where it has a unique, stable solution. The prior distribution over the productivity and demand shocks autorregresive coefficients have prior means of 0.7 and large enough standard deviations to allow for other values. To reduce the parameter space, we have assumed that the AR coefficients are the same for the same type of shock across countries (i.e $\rho^{i, j}=\rho^{i, j^{*}}$, for $i=Z, G$, and $\left.j=T, N\right)$. Different volatilities of the same type of shock across countries are allowed through different standard deviations of the innovations, which have Gamma prior distributions, to ensure positive numbers.

\section{Results}

\subsection{Posterior}

Table 6 presents the posterior mean and 90 percent confidence interval for the model's parameters. In the first column we present the estimated parameters of the "Different Trends" model, where country and sector-specific technology shocks have trends calibrated to match the sample mean of the four inflation indicators. In the "Same Trends" column we present the estimates of the model with stationary country and sector-specific technology shocks and common inflation and real growth rates across sectors and countries. Finally, the "Unrestricted" differs from the previous model because there is an unrestricted vector of constants.

The estimates of the structural parameters do not differ importantly across models, and they are quite similar to what has been obtained before in the literature. In the case of tradable goods, the posterior estimate for the Spanish tradable sector ranges between 0.65 and 0.76 , which implies average durations between optimal price changes of between 3 and 4 quarters. The estimates of the Calvo parameter for the nontradable sector in Spain also lies in a similar range of parameters. On the other hand, the estimates of the Calvo parameter in the rest of the euro area 
differ a bit more: they suggest that proces are reset optimally every 2 quarters in the tradable sector, and about 4 quarters in the nontradable sector. The degrees of backward looking behavior in the Phillips Curve are low: they amount to being below one third in the tradable sector, and one sixth in the nontradable sector, in both countries. All these results are fully consistent with the survey evidence presented by Fabiani et al. (2006).

The estimates for the Taylor rule also do not change much across model specifications and suggest that the ECB targets inflation with a large coefficient on the reaction of nominal interest rates to inflation, of about 1.6, with a significant degree of monetary policy inertia, of 0.79. Note that these estimates are not so different from the priors, such that given these, the information contained in the likelihood function does not provide additional information.

Table 6. Posterior Distributions

\begin{tabular}{|c|c|c|c|}
\hline & Different & Same & Unrestricted \\
\hline & Trends & Trends & \\
\hline$\theta_{H}$ & $\begin{array}{c}0.76 \\
(0.70-0.81)\end{array}$ & $\begin{array}{c}0.71 \\
(0.64-0.77)\end{array}$ & $\begin{array}{c}0.65 \\
(0.57-0.73)\end{array}$ \\
\hline$\theta_{F^{*}}$ & $\begin{array}{c}0.48 \\
(0.37-0.58)\end{array}$ & $\begin{array}{c}0.45 \\
(0.34-0.55)\end{array}$ & $\begin{array}{c}0.45 \\
(0.35-0.57)\end{array}$ \\
\hline$\theta_{N}$ & $\begin{array}{c}0.74 \\
(0.68-0.80)\end{array}$ & $\begin{array}{c}0.62 \\
(0.52-0.72)\end{array}$ & $\begin{array}{c}0.62 \\
(0.53-0.71)\end{array}$ \\
\hline$\theta_{N^{*}}$ & $\begin{array}{c}0.84 \\
(0.79-0.88)\end{array}$ & $\begin{array}{c}0.83 \\
(0.78-0.87)\end{array}$ & $\begin{array}{c}0.81 \\
(0.76-0.86)\end{array}$ \\
\hline$\varphi_{H}$ & $\begin{array}{c}0.29 \\
(0.04-0.52)\end{array}$ & $\begin{array}{c}0.24 \\
(0.04-0.45)\end{array}$ & $\begin{array}{c}0.37 \\
(0.05-0.67)\end{array}$ \\
\hline$\varphi_{F^{*}}$ & $\begin{array}{c}0.35 \\
(0.06-0.65)\end{array}$ & $\begin{array}{c}0.37 \\
(0.06-0.68)\end{array}$ & $\begin{array}{c}0.31 \\
(0.04-0.56)\end{array}$ \\
\hline$\varphi_{N}$ & $\begin{array}{c}0.14 \\
(0.02-0.25)\end{array}$ & $\begin{array}{c}0.23 \\
(0.02-0.44)\end{array}$ & $\begin{array}{c}0.17 \\
(0.02-0.32)\end{array}$ \\
\hline$\varphi_{N^{*}}$ & $\begin{array}{c}0.14 \\
(0.02-0.25)\end{array}$ & $\begin{array}{c}0.16 \\
(0.02-0.29)\end{array}$ & $\begin{array}{c}0.21 \\
(0.03-0.38)\end{array}$ \\
\hline$\gamma_{\Pi}$ & $\begin{array}{c}1.56 \\
(1.41-1.72)\end{array}$ & $\begin{array}{c}1.56 \\
(1.39-1.71)\end{array}$ & $\begin{array}{c}1.53 \\
(1.38-1.69)\end{array}$ \\
\hline$\rho_{R}$ & $\begin{array}{c}0.79 \\
(0.74-0.84) \\
\end{array}$ & $\begin{array}{c}0.79 \\
(0.73-0.84) \\
\end{array}$ & $\begin{array}{c}0.77 \\
(0.72-0.82) \\
\end{array}$ \\
\hline $\log \mathrm{L}$ & -153.52 & -134.41 & -46.97 \\
\hline
\end{tabular}

Interestingly, while the estimates of the structural parameters of the model do not change much across specifications, the posterior estimates for the AR coefficients of the shocks do indeed change significantly. In the model with "Different Trends", the AR coefficients are in the range between 0.96 for the tradable sector technology 
shock to 0.98 for the nontradable sector demand shock. On the contrary, the AR coefficients in the case of the "Unrestricted" model are in the range between 0.75 to 0.88 . The parameter estimates for the "Same Trends" model are in between the other two.

We compare models using the log-marginal difference, also known as the log-Bayes factor. The Bayes factor tells the researcher how she would update her priors on which model is closer to the true one after observing the data (Fernández-Villaverde and Rubio-Ramírez, 2004). The model with unrestricted constants easily beats the other two: the log-marginal differences are about 88 in one case and 107 in the other. Hence, the restrictions imposed in the first two models on inflation, growth and nominal interest rates imply a worse fit to the data.

Table 6 (cont). Posterior Distributions

\begin{tabular}{|c|c|c|c|}
\hline & $\begin{array}{c}\text { Different } \\
\text { Trends }\end{array}$ & $\begin{array}{l}\text { Same } \\
\text { Trends }\end{array}$ & Unrestricted \\
\hline$\rho^{Z, T}$ & $\begin{array}{c}0.96 \\
(0.94-0.98)\end{array}$ & $\begin{array}{c}0.92 \\
(0.87-0.97)\end{array}$ & $\begin{array}{c}0.75 \\
(0.62-0.88)\end{array}$ \\
\hline$\rho^{G, T}$ & $\begin{array}{c}0.97 \\
(0.95-0.98)\end{array}$ & $\begin{array}{c}0.95 \\
(0.93-0.97)\end{array}$ & $\begin{array}{c}0.88 \\
(0.84-0.92)\end{array}$ \\
\hline$\rho^{Z, N}$ & $\begin{array}{c}0.97 \\
(0.95-0.98)\end{array}$ & $\begin{array}{c}0.88 \\
(0.82-0.96)\end{array}$ & $\begin{array}{c}0.78 \\
(0.66-0.90)\end{array}$ \\
\hline$\rho^{G, N}$ & $\begin{array}{c}0.98 \\
(0.97-0.99)\end{array}$ & $\begin{array}{c}0.98 \\
(0.97-0.99)\end{array}$ & $\begin{array}{c}0.84 \\
(0.77-0.91)\end{array}$ \\
\hline$\sigma\left(\varepsilon_{t}^{x}\right)$ & $\begin{array}{c}0.48 \\
(0.27-0.69)\end{array}$ & $\begin{array}{c}0.39 \\
(0.22-0.55)\end{array}$ & $\begin{array}{c}0.37 \\
(0.21-0.53)\end{array}$ \\
\hline$\sigma\left(\varepsilon_{t}^{m}\right)$ & $\begin{array}{c}0.12 \\
(0.09-0.14)\end{array}$ & $\begin{array}{c}0.12 \\
(0.09-0.15)\end{array}$ & $\begin{array}{c}0.11 \\
(0.08-0.14)\end{array}$ \\
\hline$\sigma\left(\varepsilon_{t}^{Z}\right)$ & $\begin{array}{c}0.53 \\
(0.32-0.73)\end{array}$ & $\begin{array}{c}0.54 \\
(0.33-0.73)\end{array}$ & $\begin{array}{c}0.48 \\
(0.30-0.66)\end{array}$ \\
\hline$\sigma\left(\varepsilon_{t}^{Z, T}\right)$ & $\begin{array}{c}1.12 \\
(0.85-1.37)\end{array}$ & $\begin{array}{c}0.83 \\
(0.61-1.05)\end{array}$ & $\begin{array}{c}0.85 \\
(0.59-1.08)\end{array}$ \\
\hline$\sigma\left(\varepsilon_{t}^{Z, T^{*}}\right)$ & $\begin{array}{c}0.48 \\
(0.27-0.67)\end{array}$ & $\begin{array}{c}0.49 \\
(0.27-0.69)\end{array}$ & $\begin{array}{c}0.51 \\
(0.29-0.71)\end{array}$ \\
\hline$\sigma\left(\varepsilon_{t}^{Z, N}\right)$ & $\begin{array}{c}1.31 \\
(1.00-1.61)\end{array}$ & $\begin{array}{c}0.99 \\
(0.71-1.28)\end{array}$ & $\begin{array}{c}0.97 \\
(0.67-1.25)\end{array}$ \\
\hline$\sigma\left(\varepsilon_{t}^{Z, N^{*}}\right)$ & $\begin{array}{c}0.86 \\
(0.57-1.14)\end{array}$ & $\begin{array}{c}0.90 \\
(0.59-1.15)\end{array}$ & $\begin{array}{c}0.95 \\
(0.65-1.23)\end{array}$ \\
\hline$\sigma\left(\varepsilon_{t}^{G, T}\right)$ & $\begin{array}{c}3.72 \\
(3.06-4.36)\end{array}$ & $\begin{array}{c}3.96 \\
(3.35-4.58)\end{array}$ & $\begin{array}{c}2.77 \\
(2.32-3.21)\end{array}$ \\
\hline$\sigma\left(\varepsilon_{t}^{G, T^{*}}\right)$ & $\begin{array}{c}5.37 \\
(4.54-6.17)\end{array}$ & $\begin{array}{c}5.03 \\
(4.29-5.81)\end{array}$ & $\begin{array}{c}4.52 \\
(3.84-5.19)\end{array}$ \\
\hline$\sigma\left(\varepsilon_{t}^{G, N}\right)$ & $\begin{array}{c}4.24 \\
(3.61-4.98)\end{array}$ & $\begin{array}{c}4.50 \\
(3.75-5.19)\end{array}$ & $\begin{array}{c}2.48 \\
(2.09-2.87)\end{array}$ \\
\hline$\sigma\left(\varepsilon_{t}^{G, N^{*}}\right)$ & $\begin{array}{c}1.08 \\
(0.21-1.84) \\
\end{array}$ & $\begin{array}{c}1.16 \\
(0.23-2.04) \\
\end{array}$ & $\begin{array}{c}1.11 \\
(0.29-2.01) \\
\end{array}$ \\
\hline
\end{tabular}


To get a sense of why the models with restrictions in the constant terms fail, in Table 7 we present the actual first and second moments of the data, and compare them to posterior moments from the three versions of the model. The worst failure of the model where the growth rates of technology in each country and sector have been adjusted to match the four inflation variables is that it underpredicts real growth by a large margin in Spain: it predicts real quarterly growth rates of $0.28(0.15$ in the service sector) while they are 0.94 (0.95) in the data. The main problem is that in the model, in order to have higher inflation in one sector with respect to the EMU, then necessarily productivity growth has to be lower. But Spain has had both higher inflation and higher real GDP growth (in the aggregate and in the nontradable sector) and this cannot be explained by the model.

Table 7. Moments in the Models and in the Data

\begin{tabular}{l|cc|cc|cc|cc}
\hline \multirow{2}{*}{} & \multicolumn{2}{|c|}{ Data } & \multicolumn{2}{c|}{$\begin{array}{c}\text { Different } \\
\text { Trends }\end{array}$} & \multicolumn{2}{c|}{$\begin{array}{c}\text { Same } \\
\text { Trend }\end{array}$} & \multicolumn{2}{c}{ Unrestricted } \\
& Mean & SD & Mean & SD & Mean & SD & Mean & SD \\
$\Delta p^{E M U}$ & 0.47 & 0.20 & 0.47 & 0.30 & 0.47 & 0.33 & 0.47 & 0.29 \\
$\Delta p^{N, E M U}$ & 0.55 & 0.13 & 0.55 & 0.22 & 0.47 & 0.22 & 0.55 & 0.58 \\
$\Delta y^{E M U}$ & 0.59 & 0.47 & 0.59 & 0.56 & 0.59 & 0.53 & 0.59 & 0.52 \\
$\Delta p$ & 0.71 & 0.20 & 0.71 & 0.46 & 0.47 & 0.41 & 0.71 & 0.17 \\
$\Delta p^{N}$ & 0.92 & 0.22 & 0.92 & 0.59 & 0.47 & 0.57 & 0.92 & 0.24 \\
$\Delta y$ & 0.94 & 0.40 & 0.28 & 0.54 & 0.59 & 0.58 & 0.94 & 0.15 \\
$\Delta y^{N}$ & 0.95 & 0.48 & 0.15 & 0.83 & 0.59 & 0.85 & 0.95 & 0.28 \\
$r$ & 0.85 & 0.24 & 1.06 & 0.22 & 1.06 & 0.23 & 0.85 & 0.20 \\
\hline
\end{tabular}

As a result, due to the restrictions imposed by the "Different trends" model, assuming the same inflation and output growth rates across countries and sectors improves model fit. While the fit to the mean of some inflation measures (specially in Spain) is still not good, the fit to the mean of output growth in Spain improves greatly and this is likely behind the improvement in the marginal likelihood. The model with unrestricted constants does a much better job in fitting the first moments of the data, by construction, and also most second moments.

Finally, we also conducted a battery of model comparison exercises to test the hypothesis of Angeloni and Ehrman (2007) and Andrés et al. (2004) suggesting that different inflation dynamics processes could be behind persistent inflation differen- 
tials in the EMU. In all cases, introducing the restriction that the coefficients of the Phillips Curves are the same across countries in the same sector always delivered lower marginal likelihoods. While the specific numbers are not reported to save space, they always implied log-Bayes factors of at least 20 (which mean "very decisive evidence" in the Bayesian model comparison language, see Kass and Raftery, 1995) favoring the models with different coefficients in Phillips Curves.

\section{$5.2 \quad$ Impulse Responses}

In this subsection, we analyze the effects of an innovation to: (i) the euro area common component of the tradable sector technology shock $\left(\varepsilon_{t}^{Z}\right)$, (ii) the Spainspecific component of the tradable sector technology shock $\left(\varepsilon_{t}^{Z, T}\right)$,(iii) the Spainspecific nontradable sector technology shock $\left(\varepsilon_{t}^{Z, N}\right)$, (iv) a monetary policy shock $\left(\varepsilon_{t}^{m}\right)$, and (v) a government-spending shock in the nontradable sector in Spain $\left(\varepsilon_{t}^{G, N}\right)$. In all cases we present posterior mean impulse responses in the model where inflation and real growth are assumed to be the same across countries and sectors. ${ }^{18}$

Technology Shocks Figures 6-8 display the responses to the three sector-specific technology shocks. In the cases of inflation and growth, the number represents quarterly growth rates. In the case of the real exchange rate and terms of trade, defined as $t_{0} t_{t}=p_{t}^{F}-p_{t}^{H}$ (price of imports minus price of exports from the point of view of Spain), we present the evolution of the level. Also, in all cases, the numbers represent deviations from long-term trend values. There are similarities and discrepancies in the reaction of main variables to these shocks. The main similarity is that, in all cases, output growth in Spain and in the euro area increase after a productivity shock. In addition, nontradable inflation in Spain always decreases with a tradable sector technology shock: the Balassa-Samuelson effect is not present in the estimated model. On the other hand, the response of the real exchange rate depends on whether the productivity shock affects only Spain, or the Euro Area as a whole.

Under a euro area-wide tradable sector productivity innovation (Figure 6), HICP inflation declines on impact by 0.1 percent in Spain and by 0.12 percent in the euro area. Nontradable inflation also decreases but by very small amounts: it declines by 0.02 percent in Spain after several periods, and by even less in the euro area.

\footnotetext{
${ }^{18}$ Using the other models does not alter the qualitative results of this subsection.
} 

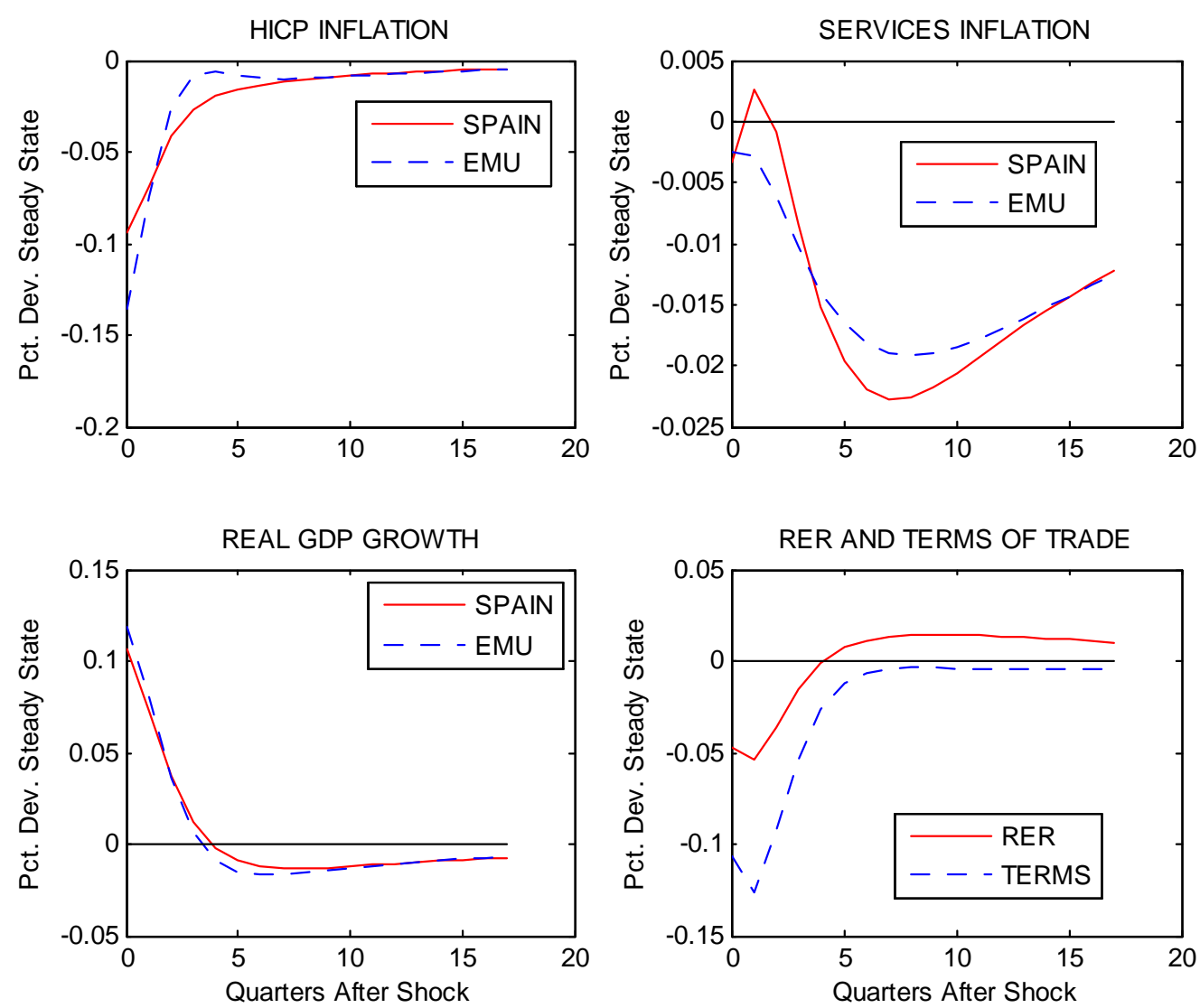

Figure 6: Impulse response to a euro area tradable sector technology shock

Hence, the Balassa-Samuelson is not present, and the behavior of headline inflation is explained mostly by the behavior of the price of tradable goods. The reason why the Balassa-Samuleson effect fails to hold is because real wages (not shown) decline in response to a technology shock. As a result, unit labor costs fall in both sectors, and hence inflation rates fall as well. The real exchange rate and the terms of trade appreciate (fall), because of a stronger response of headline and goods HICP inflation in the rest of the EMU than in Spain. Under this shock, growth increases by about 0.1 percent in Spain and in the euro area on impact, and returns fast to the long-term value. Overall, the effects of a euro area wide productivity shock are symmetric in both Spain and the rest of the euro area.

Under a Spain-only tradable sector technology shock, the effects are more asymmetric, as expected (Figure 7). The reaction of spanish variables is stronger, while the reaction of euro area variables is weaker. For the case of Spain, inflation decreases by 0.16 percent on impact, and it takes longer for inflation to return to 

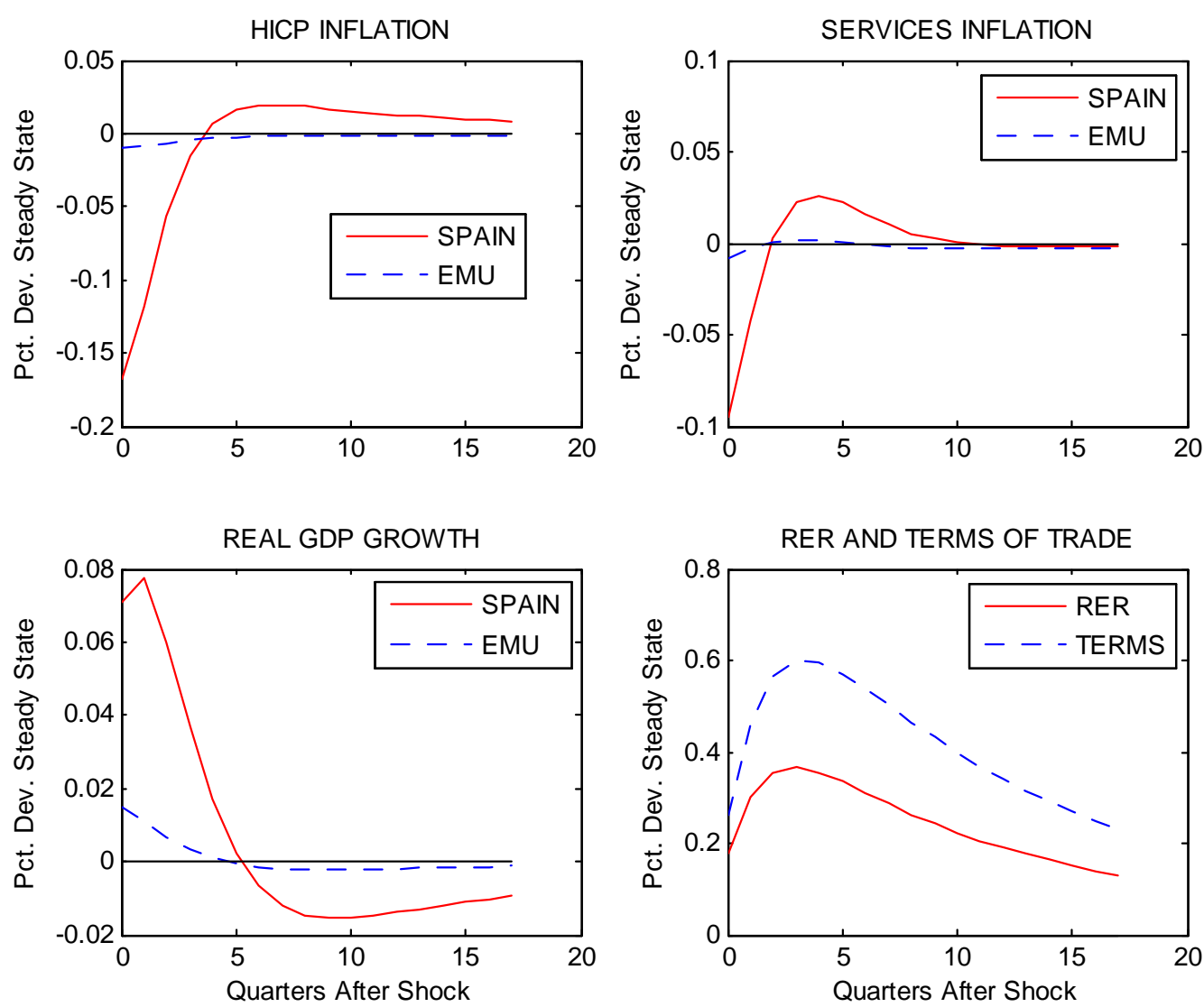

Figure 7: Impulse response to a Spain-only tradable sector technology shock.

its long-term value. Output increases on impact by 0.07 percent above trend, and displays a hump-shaped response. Nontradable inflation decreases by 0.1 percent: again, the Balassa-Samuelson effect is not present because nontradable inflation falls after an increase of technology in the tradable sector. Since both price levels fall in Spain relative to the euro area, the real exchange rate depreciates by 0.2 percent on impact and displays a hump-shaped response. Because Spain enjoys higher productivity than the rest of the euro area, the terms of trade depreciate (increase). Even though the shock is asymmetric and only affects the Spanish tradable sector, there are some spillover effects to the rest of the EMU, but the effect is quantitatively very small.

The effects of a Spain-only nontradable shock are similar to those we have described for the tradable shock, except that in this case the shock affects mostly the nontradable sector variables (Figure 8). In this case, it is nontradable inflation that declines: the impact is 0.32 percent. As a result, the headline HICP declines, since 

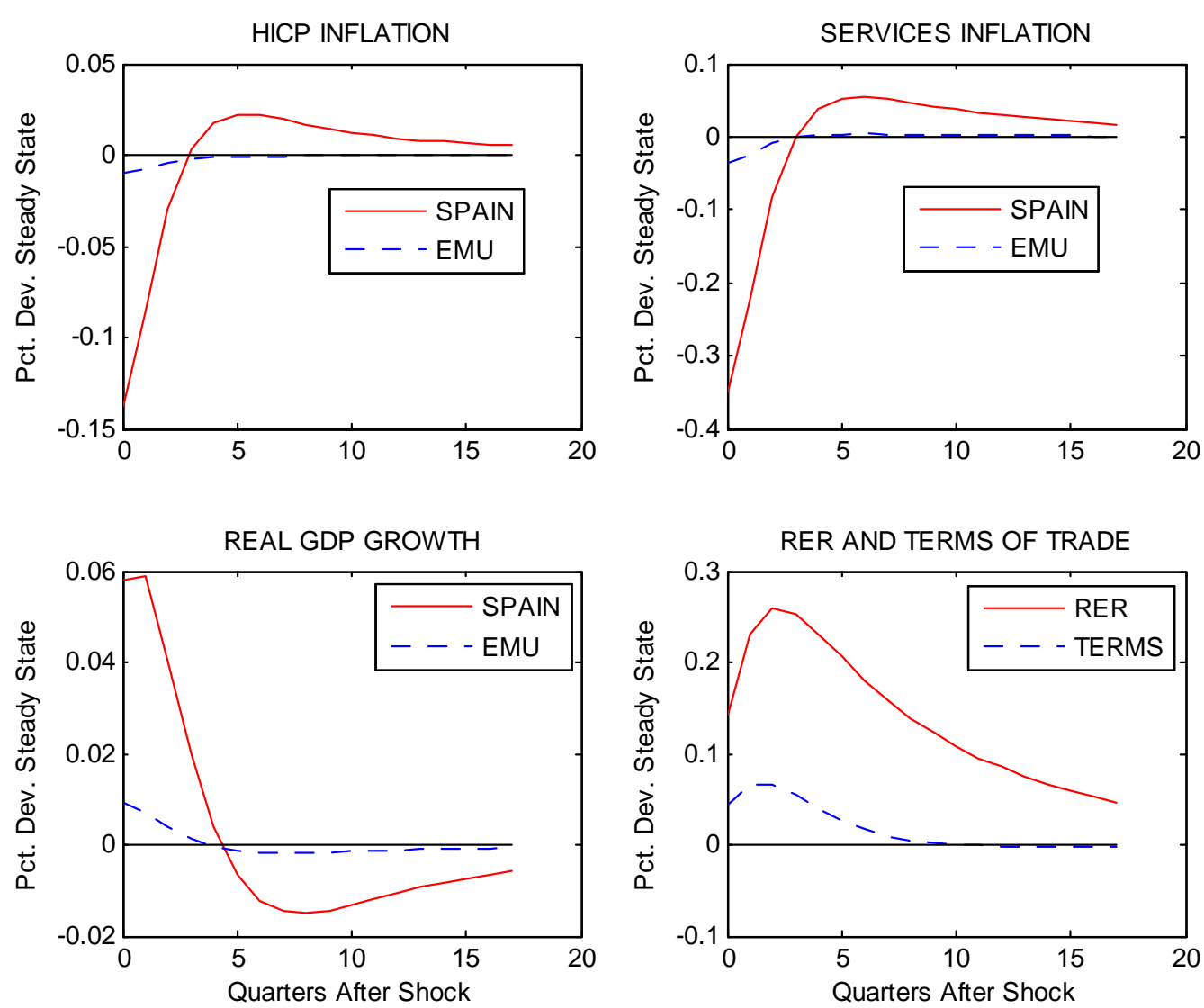

Figure 8: Impulse response to a Spain-only nontradable sector technology shock.

inflation in the tradable sector decreases by a smaller amount, and the real exchange rate depreciates. Output growth increases in Spain by 0.06 percent above trend, and displays some hump-shaped response. There some small spillover effects to the rest of the EMU, because of the reaction of monetary policy.

Monetary Policy Shocks Figure 9 displays the impulse response to a monetary policy shock that decreases the nominal interest rate by 25 basis points at an annualized rate. Similar to the case of euro area tradable productivity shocks, the effects of monetary policy are similar in Spain and the euro area. Output declines by 0.08 percent below trend after an increase of interest rates, while nontradable inflation declines about 0.12 percent below trend on impact in Spain, and half of that amount in the euro area. The impact effect of monetary policy on headline HICP inflation is similar: about 0.15 percent below trend, but the reaction of each inflation indicator is different in each country: in Spain services inflation declines more than in the 

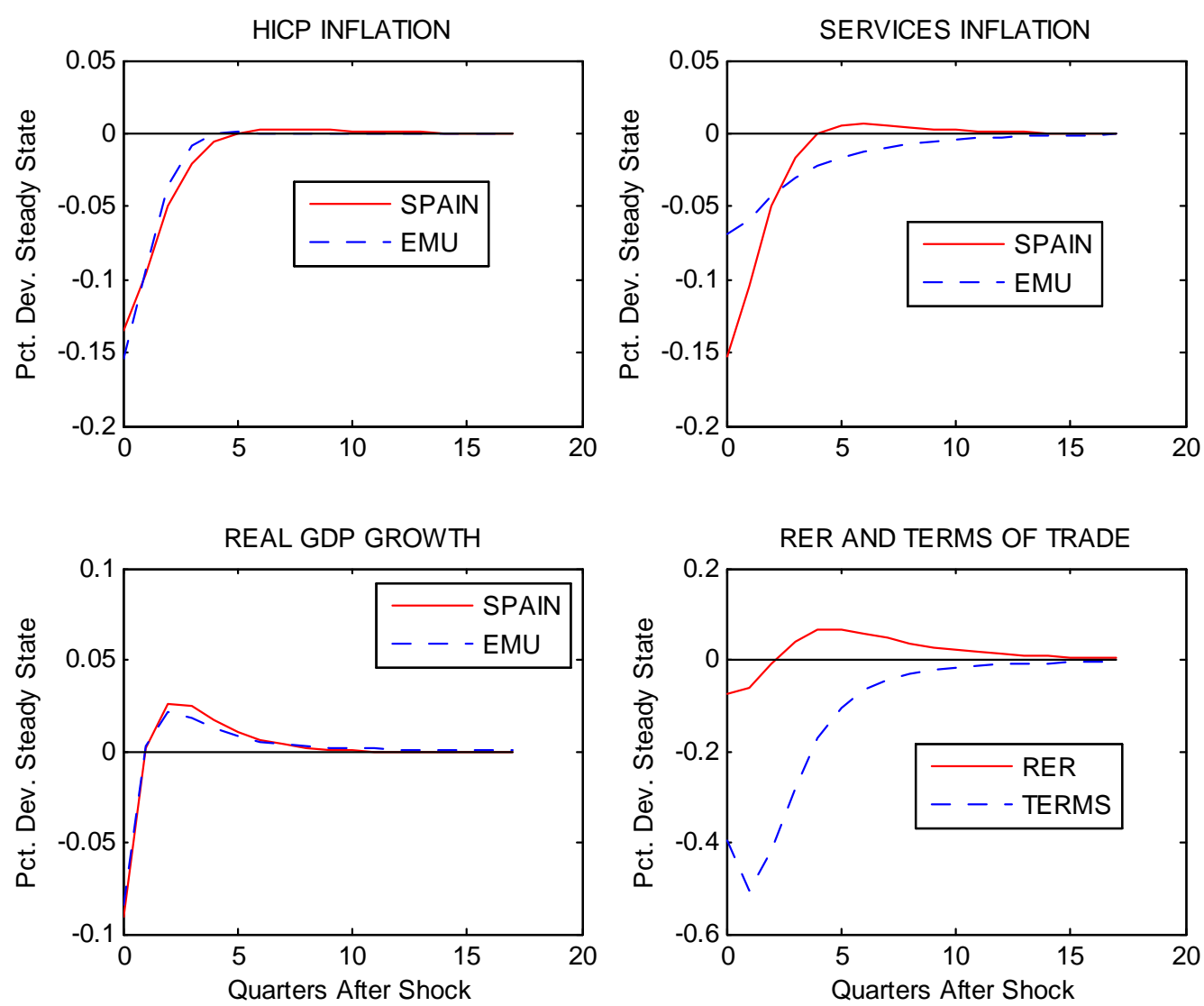

Figure 9: Impulse response to a monetary policy shock.

EMU, while the opposite happens in goods inflation, and as a result the terms of trade appreciate. The real exchange rate also appreciates, but by a small amount.

Response to a Nontradable Demand Shock The response to a nontradable demand shock is presented in Figure 10. The most important result is that output in Spain increases by 0.25 percent above trend on impact. Both nontradable and tradable inflation increase after this type of shock: the nontradable component increases because of excess demand for its product, while the tradable component increases because of the imperfect substitutability of both types of goods: tradable goods producers are able to charge higher prices and not loose market share in the Spanish market. The effects on prices are quantitatively small. In this case, the real exchange rate appreciates, because of higher inflation in both sectors in Spain. Since this shock increases nontradable inflation, output, and causes a real appreciation at the same time, López-Salido et al. (2005) suggest that this type of shock would 

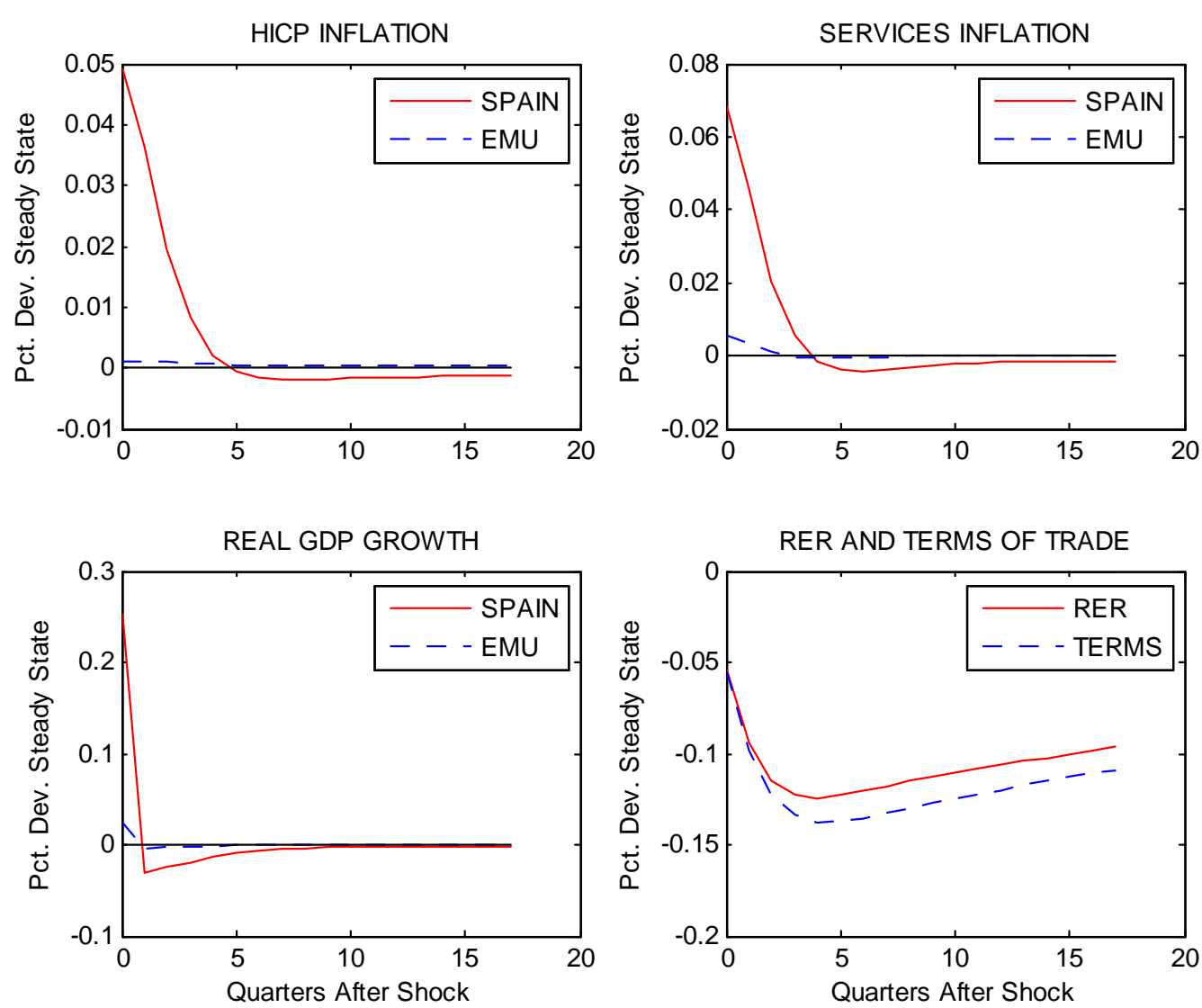

Figure 10: Impulse response to a nontradable government spending shock.

have to be a main ingredient in explaining the behavior of the Spanish economy in recent years.

\subsection{What drives inflation differentials?}

What we have learned from the previous subsection is that, most likely, a combination of shocks would be useful to explain the data. To better understand what forces are behind the behavior of main macro variables in the EMU and in Spain, in Table 8 we confront the actual standard deviation of the macro series with that implied by the estimated model, and we perform a variance decomposition exercise. ${ }^{19}$

\footnotetext{
${ }^{19}$ The variance decomposition is performed using the posterior mean of the "Same Trends" model. Using the estimates from the other models does not change the results significantly.
} 
Table 8. Second Moments

\begin{tabular}{l|c|c|ccccc}
\hline \multirow{2}{*}{} & \multicolumn{2}{|c|}{ Std. Dev. } & \multicolumn{5}{c}{ Variance Decomposition (in percent) } \\
\cline { 2 - 8 } & Data & Model & Tech. T & Tech. NT & Tech. Aggr. & Demand & Mon.Pol. \\
\hline$\Delta p^{E M U}$ & 0.20 & 0.33 & 39.0 & 6.2 & 22.6 & 8.5 & 29.8 \\
$\Delta p^{N, E M U}$ & 0.13 & 0.22 & 17.0 & 47.7 & 9.8 & 9.6 & 23.6 \\
$\Delta y^{E M U}$ & 0.47 & 0.53 & 14.2 & 2.6 & 8.4 & 79.3 & 2.8 \\
$\Delta p$ & 0.20 & 0.41 & 42.4 & 20.3 & 10.4 & 13.9 & 18.1 \\
$\Delta p^{N}$ & 0.21 & 0.57 & 9.0 & 63.1 & 1.7 & 12.8 & 11.4 \\
$\Delta y$ & 0.40 & 0.58 & 12.7 & 3.6 & 6.0 & 80.3 & 3.0 \\
$\Delta y^{N}$ & 0.48 & 0.85 & 0.4 & 13.9 & 0.2 & 84.3 & 1.0 \\
$r$ & 0.25 & 0.23 & 57.1 & 12.1 & 33.7 & 16.6 & 10.4 \\
\hline$\Delta p^{*}-\Delta p$ & 0.45 & 0.43 & 47.8 & 26.2 & 1.8 & 24.1 & 0.5 \\
\hline
\end{tabular}

Several interesting results arise. The model fit to the second moments is the same as in Table 7, but we have also added the posterior mean of the standard deviation of the inflation differential. It is quite remarkable that the model provides a good fit to this series, despite that fact that we did not enter this variable in the estimation procedure. Euro area variables are mostly explained by euro area shocks, specially euro area inflation, which is mostly driven by the aggregate technology shock (22.6 percent) and monetary policy shocks (29.8 percent). About 33.7 percent of the volatility of nominal interest rates is driven by the aggregate technology shock, and an additional 10.4 percent is driven by monetary policy shocks. Second, nontradable inflation both in Spain and the euro area is mostly driven by nontradable technology shocks, while tradable sector technology shocks have a small impact, explaining about 17 percent of nontradable inflation volatility in the euro area and 9 percent in Spain. Therefore, this confirms the finding that the Balassa-Samuelson effect is quantitatively small in the sample period we study. The demand shocks mostly explain volatility in real output growth rates, since they explain about 84.3 percent of the volatility of nontradable real output growth in Spain, and about 80 percent of the volatility of agregate output growth in the euro area and in Spain.

The main result of Table 8 is that most of the volatility in the inflation differential turns out to be explained by tradable sector technology shocks: their contribution is 47.8 percent of the variance of total volatility. Nontradable sector technology shocks explain a significant size as well, 26.2 percent, while demand shocks explain 
24.1 percent, and the rest of the shocks have marginal importance. These results are in stark contrast with the findings of Altissimo et al. (2005), who suggest that nontradable productivity shocks are a main driver of inflation differentials in the euro area. They base their explanation on overall inflation dispersion in the euro area and using evidence similar to Figure 1, where services inflation seems to be main driver of HICP inflation. In the present paper, as we have shown in Figure 3, differentials in the tradable goods sector inflation are the main driver of HICP inflation differentials between Spain and the EMU. Therefore, it could well be that explaining inflation differentials country by country would deliver different results than the Spanish case. It is important to remark that our results are similar to those of Duarte and Wolman (2002): their paper also finds that shocks to the tradable sector are a main driver of inflation differentials. Finally, as in the present paper, both Altissimo et al. (2005) and Duarte and Wolman (2002) find a small effect of fiscal or demand shocks on inflation differentials, while Angeloni and Ehrmann (2007) suggest that it is demand shocks that explain the behavior of inflation differentials in the EMU.

\section{Concluding Remarks}

The study of inflation differentials in a currency union has become important, specially after the observed increase in inflation dispersion and the persistence of inflation differentials in the euro area after the launch of the euro in January 1999. Several explanations have been suggested in the literature, that emphasize the role of tradable sector and nontradable sector technology shocks, demand shocks, and heterogeneous inflationary processes in the euro area. This paper has contrasted all these hypotheses for the case of Spain, in a two-sector, two-country DSGE model estimated with Bayesian methods. An obvious shortcoming of the paper is the short sample used to estimate the model, but the process of nominal convergence between Spain and the rest of the EMU countries is too important to be ignored, and the pre-EMU sample cannot be used in a model where coefficients could be subject to regime changes.

Rather than repeat the results of the paper, we discuss here some caveats that could apply to our results. First of all, the effects of price markup shocks (that would increase the market power of firms) and productivity shocks cannot be distinguished in the context of this model. Therefore, what we are attributing to productivity 
shocks in the tradable sector could be attributed to time-varying markups, and hence the results we provide here can be seen as an upper bound to the importance of technology shocks. Note, however, that this is simply a labelling issue, and would not change the fact that the bulk of the action to explain the inflation differential between Spain and the rest of the EMU is in the tradable sector.

Second, it could well be that the importance of the tradable sector productivity shock is picking up the effect of oil price shocks, that are not included in the model. We compute the correlation between the smoothed tradable sector technology shocks, and the energy and unprocessed food (the non-core) components of the HICP in Spain and the euro area. We find that both the common innovation to the tradable sector technology shock, $\left(\varepsilon_{t}^{Z}\right)$, and the rest of EMU innovation to the technology shock $\left(\varepsilon_{t}^{Z, T^{*}}\right)$ display a significant correlation of around 0.5 with the energy component inflation of the HICP both in Spain and the euro area. Therefore, these two innovations (but not the innovation to the tradable sector technology shock in Spain) seem to pick up high frequency movements in the HICP due to energy prices. On the other hand, the correlation between technology shocks and the unprocessed food component is close to zero and insignificant.

Finally, while the EMU is the most important trade partner of Spain (70 percent of international trade), the role of trade with third countries, the role of other commodity prices and the effects of the trade-weighted euro exchange rate should be introduced in large scale macroeconomic models. 


\section{References}

Altissimo, F., P. Benigno, and D. Rodríguez-Palenzuela, 2005, "Long-Run Determinants of Inflation Differentials in a Monetary Union," NBER Working Paper 11473.

An, S. and F. Schorfheide, 2006, "Bayesian Analysis of DSGE Models," forthcoming, Econometric Reviews.

Andrés, J., E. Ortega, and J. Vallés, 2003, "Market Structure and Inflation differentials in the European Monetary Union," Bank of Spain Working Paper 0301.

Angeloni,I., and M. Ehrmann, 2007, "Euro Area Inflation Differentials," The B.E. Journal of Macroeconomics: Vol. 7 : Iss. 1 (Topics), Article 24. Available at: http://www.bepress.com/bejm/vol7/iss1/art24.

Baxter, M. and M. Crucini, 1995, "Business Cycles and the Asset Structure of Foreign Trade," International Economic Review, vol. 36(4), pp. 821-54,

Betts, C. and T. Kehoe, 2006, "Real Exchange Rate Movements and the Relative Price of Nontraded Goods," Journal of Monetary Economics (forthcoming).

Blanchard, O., 2006, "Portugal, Italy, Spain, and Germany. The Implications of a Suboptimal Currency Area," mimeo, MIT.

Burnstein, A., M. Eichenbaum, and S. Rebelo, 2005, "Large Devaluations and the Real Exchange Rate," Journal of Political Economy, Vol. 113, No. 4, pp. 742-784.

Canova, F. and Sala, L., 2006, "Back to square one: identification issues in DGSE models", ECB Working Paper 583.

Chari, V.V., P. Kehoe and E. McGrattan, 2002, "Can Sticky Price Models Generate Volatile and Persistent Real Exchange Rates?," Review of Economic Studies, Vol. 69, pp. 533-563.

Duarte, M., and A. Wolman, 2002, "Regional Inflation in a Currency Union: Fiscal Policy versus Fundamentals," International Finance Discussion Paper 746, Board of Governors of the Federal Reserve System.

ECB, 2003, "Inflation Differentials in the Euro Area: Potential Causes and Policy Implications."

Engel, C., 1999, "Accounting for U.S. Real Exchange Rate Changes," Journal of Political Economy, Vol. 107, No. 3, pp. 507-538. 
Fabiani, S., M. Druant, I. Hernando, C. Kwapil, B. Landau, C. Loupias, F. Martins, T. Mathä, R. Sabbatini, H. Stahl, and A. Stokman, 2006, "What Firms' Surveys Tell Us About Price-Setting Behavior in the Euro Area," International Journal of Central Banking, Vol. 2, Number 3, pp. 3-47.

Fagan, G., J. Henry, and R. Mestre, 2001, "An Area-Wide Model (AWM) for the Euro Area," European Central Bank Working Paper No. 42.

Fernández-Villaverde, J., and J.F. Rubio-Ramírez, 2004, "Comparing Dynamic Equilibrium Models to Data: A Bayesian Approach," Journal of Econometrics, Vol. 123, pp. $153-187$.

Galí, J. and P. Rabanal, 2005, "Technology Shocks and Aggregate Fluctuations: How Well Does the RBC Model Fit Postwar U.S. Data?," in M.Gertler and K. Rogoff (eds.), NBER Macroeconomics Annual, Vol. 19, pp. 225-288.

Ireland, P., "Technology Shocks in the New Keynesian Model" Review of Economics and Statistics, Vol. 86, No. 4, pp. 923-936.

Kass, R. E. and Raftery, A. E., 1995, "Bayes Factors", Journal of the American Statistical Association 90, issue 430, pp.773-795.

King, Robert, Plosser, C. and S. Rebelo, 1988, "Production, Growth and Business Cycles, I: The Basic Neo-classical Model," Journal of Monetary Economics, Vol. 21, no. 2/3, pp. 195-232.

López-Salido, J. D., F. Restoy and J. Vallés, 2005, "Inflation Differentials in EMU: The Spanish Case," Bank of Spain Working Paper 0514.

Lubik, T. and F. Schorfheide, 2004. "Testing for Indeterminacy: An Application to U.S. Monetary Policy," American Economic Review, vol. 94(1), pp. 190-217.

Pytlarczyk, E., 2005, "An Estimated DSGE Model for the German Economy within the Euro Area," Bundesbank Discussion Paper, Series 1: Economic Studies, No $33 / 2005$.

Rabanal, P. and J.F. Rubio-Ramírez, 2005, "Comparing New Keynesian Models of the Business Cycle: A Bayesian Approach," Journal of Monetary Economics, Vol. 52, No. 6, pp. 1151-1166.

Rabanal, P. and V. Tuesta, 2006, "Real Exchange Rate Dynamics in an Estimated Two Country Model: What is Important and What is not," CEPR Discussion Paper 
5957.

Rogers, J., 2006, "Monetary Union, Price Level Convergence, and Inflation: How Close is Europe to the United States?," Journal of Monetary Economics (forthcoming). Also International Finance Discussion Paper 2002-740, Board of Governors of the Federal Reserve System.

Roubini, N., Parisi-Capone, E., and C. Menegatti, 2007, "Growth Differentials in the EMU: Facts and Considerations," RGE, mimeo.

Schmitt-Grohé, S. and M. Uribe, 2006, "Optimal Fiscal and Monetary Policy in a Medium-Scale Macroeconomic Model," in M.Gertler and K. Rogoff (eds.), NBER Macroeconomics Annual, Vol. 20, pp. 383-425.

Smets, F. and R. Wouters, 2003, "An Estimated Stochastic Dynamic General Equilibrium Model for the Euro Area," Journal of the European Economic Association, Vol. 1, No. 5, pp. 1123-1175. 


\section{A Appendix: Different Inflation Rates in the Steady State}

In the steady-state, we have that:

$$
\frac{\hat{p}^{N}}{P^{N}}=\frac{\sigma}{(\sigma-1)} \frac{M C^{N}}{P^{N}}
$$

From the evolution of prices under Calvo pricing:

$$
\left(\frac{\hat{p}^{N}}{P^{N}}\right)^{1-\sigma}=1
$$

Therefore:

$$
\frac{M C^{N}}{P^{N}}=\frac{(\sigma-1)}{\sigma}
$$

Similarly, for the tradable sector:

$$
\frac{M C^{H}}{P^{H}}=\frac{(\sigma-1)}{\sigma}
$$

Since real wages are the same in the two sectors, then :

$$
\begin{aligned}
& \frac{M C^{N}}{P^{N}}=\frac{\tilde{W}}{Z^{N}} \frac{P}{P^{N}} \\
& \frac{M C^{H}}{P^{H}}=\frac{\tilde{W}}{Z^{T}} \frac{P}{P^{H}}
\end{aligned}
$$

Dividing the previous expressions, we arrive at the following final expression:

$$
\frac{Z^{T}}{Z^{N}} \frac{P^{H}}{P^{N}}=1
$$

Hence, in the steady state the ratio of price levels will grow at different rates if productivity in the two sectors grow at different rates. 